Market Work, Home Production, Consumer Demand and Unemployment among the Unskilled

Melanie Lührmann and Matthias Weiss

101-2006

January, 2006 


\title{
Market Work, Home Production, Consumer Demand and Unemployment among the Unskilled*
}

\author{
Melanie Lührmann and Matthias Weiss ${ }^{\dagger}$
}

April 4, 2006

\begin{abstract}
We develop a general equilibrium model in which longer working time and higher labor force participation lead to a fall in unemployment. Longer working hours and higher labor force participation have two direct effects: People have higher incomes and less (leisure) time. This has implications for the composition of consumer demand, since people spend less time on home production. Instead, they outsource more domestic tasks to the market. Consumer demand shifts toward unskill-intensive goods. The relative demand for unskilled labor rises and unemployment falls.

We provide empirical evidence for our theoretical predictions in several ways: We study the link between labor market participation, home production and the demand for household and similar services using the German time use survey conducted in 1991/92. In addition, we use panel data for 23 OECD countries between 1980 and 2003 to directly examine the link between labor force participation and the unemployment rate. The empirical results corroborate the predictions from the theoretical model.
\end{abstract}

Keywords: Working Time Reduction, Labor Force Participation, Low Skill Employment, Home Production, Time Use

JEL Classification: J22, J23, E21, E24

\section{Introduction}

In this paper, we present and test a general equilibrium model in which increases in labor supply trigger an increase in the relative demand for unskilled labor and therefore improve the labor market prospects of unskilled workers. This feedback effect works through changes in the composition of consumer demand respectively changes in home production.

\footnotetext{
${ }^{*}$ We are grateful to Rob Alessie, Axel Börsch-Supan, Alfred Garloff, Dan Hamermesh, Karsten Hank, Florian Heiss, Martin Hellwig, Hendrik Jürges, Winfried Müller and Joachim Winter for valuable comments and suggestions. The usual disclaimer applies.

${ }^{\dagger}$ MEA -Mannheim Research Institute for the Economics of Aging, Universität Mannheim, L13,17, D68131 Mannheim. Email addresses: luehrmann@mea.uni-mannheim.de, weiss@mea.uni-mannheim.de.
} 
We consider three margins at which labor supply can change: labor force participation, (weekly) working time and retirement age. Debates on increasing versus cutting down on weekly working time,${ }^{1}$ prolonging working life by raising the retirement age ${ }^{2}$ and increasing labor force participation particularly among women resurface periodically in the political discussion. The arguments against or in favor of these policy measures are well known. Opponents of increased labor market participation think that - for want of jobs - it does not make much sense to have people work longer (hours or years) or to have more people enter the labor force in times of high unemployment. This view is based on what has become known as the "lump of labor fallacy". It does not take into account that changes in labor supply entail changes in income and consumer demand and thus ultimately in labor demand. In other words, the amount of work to be done is not a fixed lump. This idea that the economy adjusts to changes in labor supply - at least in the long run - is well established among economists. Empirical studies on employment effects of working time reduction are inconclusive. They generally suffer from the fact that changes in working time usually involve changes in unit wage costs (e.g., working time reduction with compensatory wage increases) and the effects of the two are hard to separate (Calmfors and Hoel 1988; Calmfors and Hoel 1989; Hunt 1999; Logeay and Schreiber 2006). A thorough review of the literature can be found in OECD (1998), pp. $117-148 .^{3}$

This paper presents and empirically analyzes a new argument in this old debate. While a voluminous empirical and theoretical literature on the employment effects especially of working time reduction already exists, very few studies look at how different types of workers are affected by these measures. ${ }^{4}$ In this paper, we show that changes in labor supply effectuate changes not only in the level but also in the composition of the demand for labor.

We consider an economy where neither wages nor productivities are affected by changes in working time or labor force participation. The effects we find in our model are thus independent of the arguments given in Footnote 3. A rise in working time or labor force participation has two direct effects: Workers have higher incomes and less (leisure) time. This change in the endowment of people is likely to have effects on the composition of consumer demand. People with higher incomes can consume more. At the same time, they

\footnotetext{
${ }^{1} \mathrm{An}$ increasing number of firms in Europe is currently returning to longer working hours in the face of increasing global competition.

${ }^{2}$ Measures to increase retirement age have been set in place and are currently being discussed again in order to finance pay-as-you-go funded social security systems in times of population aging.

${ }^{3}$ Calmfors and Hoel (1989) give five reasons of why working time reduction might actually lead to a reduction in labor demand: (i) Wage rates per unit of time may rise. (ii) Even if wage rates remain constant, wage costs per unit of time may rise due to the existence of fixed costs per employee. (iii) Labor productivity per hour may fall because the proportion of "non-productive" time devoted to starting up and finishing work may rise. (iv) The factor cost of employing new workers rises relative to the cost of increasing overtime when standard hours are cut. (v) Capital utilization will decrease to the extent that the operating time of the capital stock is reduced pari passu with working time.

${ }^{4}$ Corneo (1995) is a notable exception.
} 
have less time at their disposal. Due to these endowment changes, they raise expenditures on those goods or services, that they have "produced" on their own so far. Examples of such outsourcing of home production are house cleaning, preparing food (using a pizza delivery service rather than making it at home,...), car washing, fixing bicycles, ironing shirts, walking dogs, repairs at home, do-it-yourself, child care, etc. The goods that everyone can make on their own are exactly those that can be "produced" by unskilled workers. So, as a consequence of growing labor supply, consumer demand shifts towards goods and services that are supplied mostly by unskilled workers and the relative demand for unskilled labor rises.

In the model economy considered in this paper, individuals maximize their utility over consumption and leisure and allocate their time over three types of activities: market work, home production, and leisure. Consumption is not equal to expenditures in our model, but consists of goods and services purchased on the market as well as self-produced goods. ${ }^{5}$ We study the effects of changes in labor market participation in the absence of compensatory wage changes or any other change in unit labor costs. Hence, our argument is independent of potential union or policy-induced wage-setting schemes. Unemployment in this model emerges because wages are downwardly rigid. ${ }^{6}$ The adverse effects of this rigidity of wages are (obviously) especially strong at the lower end of the skill distribution. Given this concentration of unemployment at unskilled labor, exogenous changes that increase the demand for products that are intensive in the use of unskilled labor have positive employment effects. The employment effects are shown to be more severe, the more complementary are the consumer goods and leisure.

In the second part of this paper, we provide empirical evidence for the basic mechanisms of our model. We analyze the empirical link between market work, home production and the demand for goods and services that are substitutes for home production at the household level, and we investigate the macroeconomic relation between labor supply measures and unemployment.

We proceed in three steps: First, we use the German time use survey from 1991/92 and investigate whether the time spent on home production activities differs by household labor supply. We find evidence of decreasing time spent on home production upon higher labor supply, encompassing working hours and labor force participation. However, looking at the allocation of time does not clarify whether home production is simply reduced without any compensatory outsourcing. ${ }^{7}$ Complementarily, we also look at a well-defined subset of services substituting for home production using the same survey and analyze whether outsourcing increases upon higher labor supply. Again, we find evidence supporting our

\footnotetext{
${ }^{5}$ The argument that consumption is more than expenditures goes back to Becker (1965) and Gronau (1977)

${ }^{6}$ Labor market frictions that entail downward rigidity of wages include unemployment benefits, minimum wages, welfare aid, wage-compression due to strong unions, etc.

${ }^{7}$ In the following, we will use the term "outsourcing" to describe the act of buying household services and other home-producible goods and services instead of producing them in the household.
} 
prediction, that outsourcing increases when market work rises. The third mechanism of our model, that this increased outsourcing of home production raises the demand for unskilled labor, cannot be quantified using this data, since there is no matching information on sectoral production functions. Hence, we use macroeconomic panel data on OECD countries and directly test the reduced form relation between labor supply measures and unemployment. The results corroborate the prediction from the theoretical model.

A number of studies has provided empirical support for some of the mechanisms of our model: The research project DEMPATEM surveyed in Schettkat and Salverda (2004) presents evidence that the demand for services in general has increased over time, partly due to the increased labor force participation of women. The focus of DEMPATEM is on international differences in the structure of consumer demand, especially in the types of services demanded. The German case study in this international comparison project analyzes the determinants of changes in the structure of consumer demand, including labor force participation as an explanatory variable (Van Deelen and Schettkat 2004). However, the authors only investigate the differences between workers and nonworkers and do not take into account the amount of time worked. They find that "the second earner seems to push up (general) service expenditures".

Special attention to household services is given in Brück, Haisken-DeNew, and Zimmermann (2003). They show that the demand for household services is very income-elastic, and that there is potentially a large market for such services. We additionally show, that not only an increasing income, but also the decrease in disposable time raises the demand for household services and other substitutes for home production. Both effects together imply that increased labor supply can create jobs for the unskilled - via changes in consumer demand.

The remainder of the paper is organized as follows: In Section 2, we develop the theoretical model. In Section 3, we provide empirical support for the theoretical predictions of our model. Conclusions are drawn in Section 4.

\section{The theoretical model}

The economy is populated by a continuum of measure 1 of heterogeneous households indexed by skill level $j \in[0,1]$. Within each household, all members have the same skill level. For simplicity, we assume that the entire age distribution is represented in each household. A share $\lambda$ of household members per cohort participates in the labor force. Working age ranges from 0 to retirement age $\rho$. Life ends at age 1. For a worker's labor market prospects, only the skill level plays a role while age (as long as it is below $\rho$ ) is irrelevant. Working time per worker is $\omega$ units of labor per period. Labor supply of each household $\xi$ is equal to the individual working time $\omega$ times the integral over all cohorts (within that household) from 0 to $\rho$ and over those workers who actually participate in 
the labor force:

$$
\xi=\rho \cdot \lambda \cdot \omega .
$$

In order to be able to make comparative statics with respect to labor supply, we model $\lambda$, $\rho$, and $\omega$ as exogenous. For simplicity, we set these parameters equal across households, skill-levels, and cohorts. Heterogeneity with respect to these parameters would amplify the complexity of the model without generating any further insights. Households have preferences over two consumer goods and leisure, and can engage in home production. Unemployment arises because of a minimum wage which depends on the average income level (see Subsection 2.2). ${ }^{8}$

\subsection{Production in firms}

Both goods are produced by a continuum of measure 1 of homogeneous firms using all types of labor. Good $h$ can be produced at home or purchased, while good $m$ is a pure market good, that can only be purchased. Good $m$ is chosen as numéraire. The technology for good $i$ is

$$
y_{i}=\int_{0}^{1} e^{\left(1+\chi_{i}\right) \cdot j} \cdot n_{i, j} \cdot d j
$$

where $n_{i, j}$ is labor input of skill type $j$ for the production of good $i$. Marginal productivity $\frac{\partial y_{i}}{\partial n_{i, j}}=e^{\left(1+\chi_{i}\right) \cdot j}$ is increasing with skill level $j$ for both goods. ${ }^{9} \chi_{i}$ is a productivity parameter reflecting differential comparative advantage of skills. $\chi_{m}>\chi_{h}$ implies that the production of good $m$ is more skill-intensive, i.e., the productivity advantage of workers with higher skills (higher $j$ ) is larger in sector $m$. For simplicity, we set $\chi_{h}=0$ and $\chi_{m}=\chi>0$. Firms act as price-takers on input and output markets. Maximizing profits

$$
\pi_{i}=p_{i} \cdot \int_{0}^{1} e^{\left(1+\chi_{i}\right) \cdot j} \cdot n_{i, j} \cdot d j-\int_{0}^{1} w_{j} \cdot n_{i, j} \cdot d j
$$

leads to demand for type $j$ labor in sector $i$ :

$$
n_{i, j}^{d}=\left\{\begin{array}{ccc}
\infty & \Leftrightarrow & w_{j}<p_{i} \cdot e^{\left(1+\chi_{i}\right) \cdot j} \\
{[0, \infty)} & \Leftrightarrow & w_{j}=p_{i} \cdot e^{\left(1+\chi_{i}\right) \cdot j} \\
0 & \Leftrightarrow & w_{j}>p_{i} \cdot e^{\left(1+\chi_{i}\right) \cdot j}
\end{array}\right.
$$

where $w_{j}$ is the wage for type $j$ labor and $p_{i}$ is the price of good $i$.

Figure 1 illustrates the allocation of types to sectors. On the horizontal axis is the space of types. On the vertical axis are the equilibrium wages in the two sectors as functions of the type $j$. Workers supply labor to the firm that offers the highest wage. In

\footnotetext{
${ }^{8}$ If wages were perfectly flexible, i.e., without unemployment, the model would yield similar effects: An increase in market work would lead to higher employment, especially among the unskilled, and to a decrease in wage inequality. Only if labor demand were perfectly inelastic, employment would remain unchanged and we would only observe a change in wage inequality.

${ }^{9}$ The exponential specification implies that the distribution of labor income is skewed to the right.
} 
Figure 1: Allocation of Types $j$ to Sectors

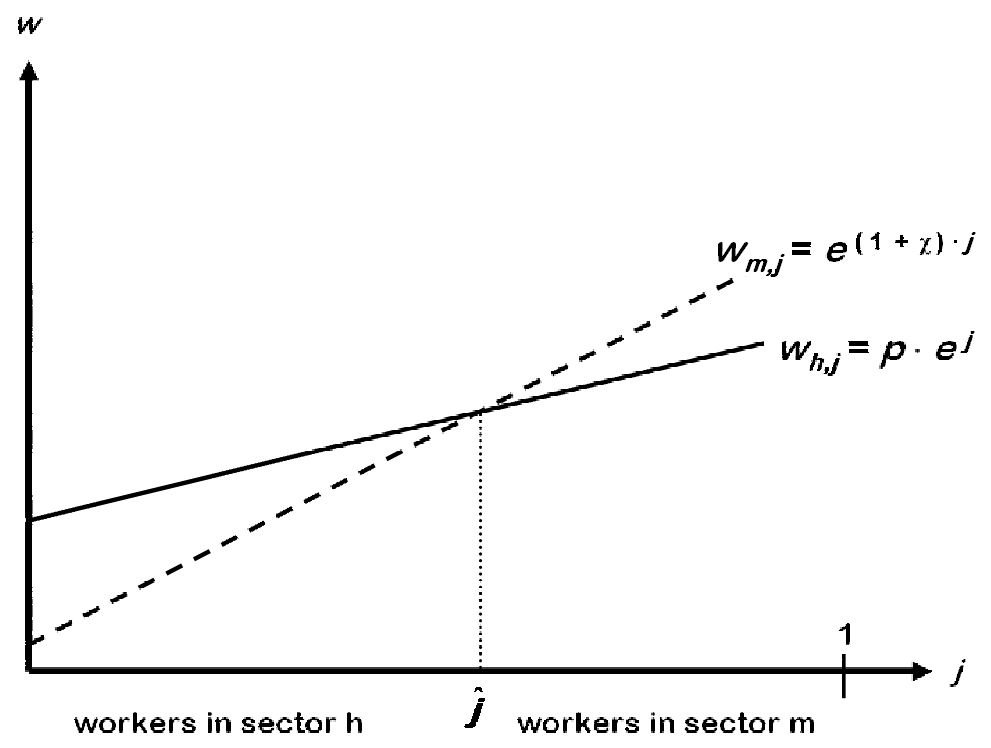

equilibrium, firms in sector $h$ pay $w_{j}=p \cdot e^{j}$ while firms in sector $m$ pay $w_{j}=e^{(1+\chi) \cdot j} \cdot{ }^{10}$ This difference in wages determines the allocation of types to sectors. Type $\hat{\jmath}=\ln p^{\frac{1}{\chi}}$ is indifferent between working in sector 1 and working in sector 2. All lower types prefer working in sector 1 while all higher types prefer working in sector 2 . The higher is the relative price of good 1 , the more skill types prefer to work in sector 1 . The productivity advantage $\chi$ of sector 2 has a negative direct effect on $\hat{\jmath}$ but an indirect effect through $p$ which might counteract the direct effect. For a discussion of the interaction between these two effects, see Weiss (2004).

Equilibrium wages for different types of workers are thus

$$
w_{j}=\left\{\begin{array}{cl}
p \cdot e^{j} & \Leftrightarrow j<\ln p^{\frac{1}{\chi}} \\
e^{(1+\chi) \cdot j} & \Leftrightarrow j \geq \ln p^{\frac{1}{\chi}}
\end{array}\right.
$$

Retirement age $\rho \in[0,1]$, labor force participation $\lambda \in[0,1]$, and fixed working time $\omega \in[0,1]$ restrict labor supply of households at each skill level $j$ to $\xi \in[0,1]$. Labor supply in the two sectors is thus given by

$$
n_{h, j}^{s}=\left\{\begin{array}{cll}
\xi & \Leftrightarrow j<\ln p^{\frac{1}{\chi}} \\
\in[0, \xi] & \Leftrightarrow j=\ln p^{\frac{1}{\chi}} \\
0 & \Leftrightarrow j>\ln p^{\frac{1}{\chi}}
\end{array} \quad n_{m, j}^{s}=\left\{\begin{array}{cl}
0 & \Leftrightarrow j<\ln p^{\frac{1}{\chi}} \\
\xi-n_{1, j}^{s} & \Leftrightarrow j=\ln p^{\frac{1}{\chi}} \\
\xi & \Leftrightarrow j>\ln p^{\frac{1}{\chi}}
\end{array} .\right.\right.
$$

Goods supply is given by

$y_{h}=\int_{0}^{\ln p^{\frac{1}{\chi}}} e^{j} \cdot \xi \cdot d j=\xi \cdot\left(p^{\frac{1}{\chi}}-1\right) \quad y_{m}=\int_{\ln p^{\frac{1}{\chi}}}^{1} e^{(1+\chi) \cdot j} \cdot \xi \cdot d j=\xi \cdot \frac{e^{1+\chi}-p^{\frac{1+\chi}{\chi}}}{1+\chi}$

\footnotetext{
${ }^{10}$ The price of the numéraire, good $m$, is normalized to 1 . We assume that parameter constellations are such that production is positive in both sectors. This implies a relative goods price $p=\frac{p_{h}}{p_{m}}$ larger than 1 .
} 
Supply of good $h(m)$ is increasing (decreasing) in the relative goods price $p$. Supply of both goods is increasing in labor supply $\xi$. $\chi$ which represents the productivity advantage of sector $m$ has a negative (positive) effect on the supply of good $h(m)$.

\subsection{Wage rigidity and unemployment}

Unemployment in this model is due to a downward rigidity of wages. We assume that the wage cannot fall below a minimum $\tilde{w}$ which is indexed to the average income level in the economy. ${ }^{11}$ This assumption introduces a rigidity that keeps relative wages from adjusting perfectly to changes in relative labor demand. Therefore, changes in relative labor demand affect employment. This sort of rigidity in the relative wage arises if strong unions ensure a compressed wage structure, if a legal minimum wage exists that is indexed to the average wage, or if welfare aid or unemployment benefits depend on the average income. Another source of such a rigidity in the relative wage could be considerations of fairness as, e.g., put forward in the "fair wage-effort hypothesis" by Akerlof and Yellen (1988) and Akerlof and Yellen (1990) and recently confirmed in a series of experimental studies surveyed by Fehr and Gächter (2000). ${ }^{12}$ In this model, $\tilde{w}$ should be seen as a simple means to capture all these phenomena leading to a rigidity in the relative wage. ${ }^{13}$

We assume that the "minimum wage" $\tilde{w}$ is a constant fraction $\theta$ of the average wage:

$$
\tilde{w}=\theta \cdot \int_{\tilde{j}}^{1} w_{j} \cdot d j=\theta \cdot\left(\frac{\chi \cdot p^{\frac{1+\chi}{\chi}}+e^{1+\chi}}{1+\chi}-p \cdot e^{\tilde{j}}\right)
$$

where $\tilde{j}$ is the type whose market wage is equal to the minimum wage. All higher types receive higher wages while all lower types are unemployed. So, $\tilde{j}$ also represents the fraction of unemployed workers.

The unemployment rate $\tilde{j}$ is determined by the equality of the minimum wage $\tilde{w}$ and the market wage of a type $\tilde{j}$ worker, $w_{\tilde{j}}$ :

$$
\theta \cdot\left(\frac{\chi \cdot p^{\frac{1+\chi}{\chi}}+e^{1+\chi}}{1+\chi}-p \cdot e^{\tilde{j}}\right) \stackrel{!}{=} p \cdot e^{\tilde{j}}
$$

\footnotetext{
${ }^{11}$ In France, Japan, Spain (among others), the statutory minimum wage is explicitly indexed to the average wage (see Cahuc and Zylberberg (2004), page 715). In other countries, this link might not be as explicit, but by and large, wages at the lower end of the distribution are usually somehow tied to the evolution of average wages over time. This assumption is not crucial for the results. On the contrary, the endogeneity of the minimum wage is moderating the employment effect of changes in labor supply.

${ }^{12}$ The fair wage-effort hypothesis is motivated by equity theory in social psychology and social exchange theory in sociology. According to this hypothesis, workers withdraw effort as their actual wage falls short of what they consider their "fair wage". Such behavior causes unemployment by introducing a downward rigidity in wages. Kahnemann, Knetsch, and Thaler (1986) have shown that individual conceptions of fair wages often diverge substantially from the levels that would clear competitive labor markets. See Weiss and Garloff (2005) for a detailed discussion of causes and effects of rigidities in the relative wage.

${ }^{13}$ In a system of union wages classified by skill levels, $\tilde{w}$ can be seen as the lowest wage level in this classification. For ease of labeling, we will in the remainder of the paper refer to $\tilde{w}$ as the minimum wage.
} 
Solving for $\tilde{j}$ yields the following lemma.

Lemma 1 The rate of unemployment $\tilde{j}$ is given by

$$
\tilde{j}=\ln \left(\frac{\theta}{1+\theta} \cdot \frac{\chi \cdot p^{\frac{1+\chi}{\chi}}+e^{1+\chi}}{p \cdot(1+\chi)}\right) .
$$

It is increasing in $\theta$ and decreasing in $p$.

Not surprisingly, the more generous is the minimum wage (the higher $\theta$ ), the higher is the rate of unemployment.

The effect of the relative goods price $p$ corresponds to the so-called Stolper-SamuelsonEffect in trade theory. An increase in the relative price of good $h$ leads to an increase in the relative demand for lower types of labor (in which the production of good $h$ is intensive). This change in relative labor does not fully translate into respective changes in the relative wage so that employment increases. ${ }^{14}$

Note that working life $\rho$, working time $\omega$, and labor force participation $\lambda$ do not have any direct effect on unemployment $\tilde{j}$ in the model. It is shown in the next section that they affect employment through their effect on the relative goods price $p$.

Figure 2: Allocation of Types $j$ to Sectors and Unemployment

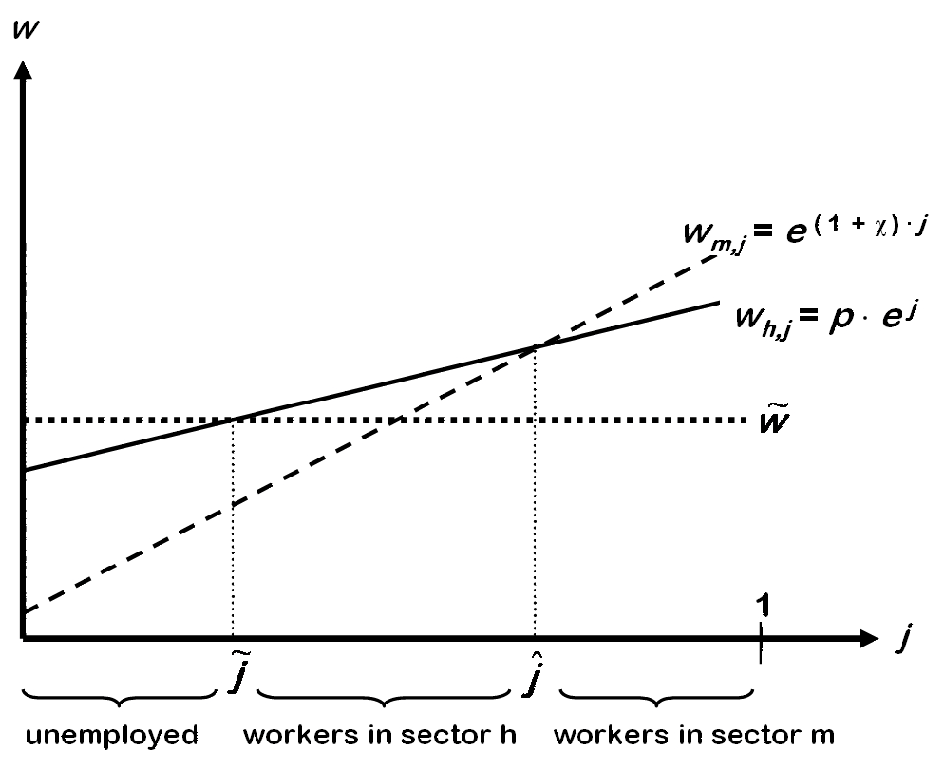

Figure 2 illustrates the effect of the minimum wage on employment. For the high types, the wage they can earn in sector $m$ exceeds the wage they would receive in sector $h$. Therefore, they work in sector $m$. The medium range types earn a higher wage in sector $h$ than in sector $m$. These types work in sector $h$. The low types, whose market value in both sectors falls short of the minimum wage, cannot find a job.

\footnotetext{
${ }^{14}$ If wages were perfectly flexible, unemployment would not exist and an increase in labor supply wouldvia this Stolper-Samuelson-Effect-translate into a decrease in wage inequality.
} 
An increase in the relative price of good $h, p$, exerts an upward pressure on the wage in sector $h$. In terms of Figure 2, an increase in $p$ implies an upward shift of the solid line. For the highest unemployed types, the wage is pushed above the minimum wage. They find employment, so that total unemployment decreases. ${ }^{15}$

The effect of labor supply on the relative goods price $p$ depends on consumer demand which is analyzed in the next subsection.

\subsection{Consumption and home production}

All households share the same preferences over consumption and leisure

$$
U_{j}\left(c_{h, j}, c_{m, j}, l_{j}\right)=\left(c_{h, j}^{\gamma}+c_{m, j}^{\gamma}+l_{j}^{\gamma}\right)^{\frac{1}{\gamma}}
$$

where $l_{j}$ is leisure time of a type $j$ household, $c_{i, j}$ is consumption of good $i$, and $\sigma=\frac{1}{1-\gamma}$ is the elasticity of substitution between consumption of good $h$, consumption of good $m$, and leisure. ${ }^{16}$

Good $h$ is either bought on the market at price $p$ or produced at home with technology

$$
y_{h, j}^{h p}=\alpha \cdot h p_{j}
$$

where $h p_{j}$ is the time that a type $j$ household devotes to home production and $\alpha$ is a productivity parameter. We assume that at home, skill types do not differ in productivity. This assumption is made for simplicity. It has no qualitative effect on the results as long as lower types have a comparative advantage in the production of the good that can be produced at home. Good $m$ is bought on the market at price 1 .

For employed households, the budget and time constraints are respectively

$$
p \cdot\left(c_{h, j}-y_{h, j}^{h p}\right)+c_{m, j}=w_{j} \cdot \xi \quad \text { and } \quad l_{j}+h p_{j}+\xi=1
$$

For unemployed households, the budget and time constraints are respectively ${ }^{17}$

$$
p \cdot\left(c_{h, j}-y_{1, j}^{h p}\right)+c_{m, j}=0 \quad \text { and } \quad l_{j}+h p_{j}=1
$$

\footnotetext{
${ }^{15}$ The intersection between the solid line (wage in sector $h$ ) and the dotted line (minimum wage) moves to the left. In fact, the dotted line (the minimum wage) shifts upward as well, but this shift is less pronounced because the minimum wage is indexed to both, the wage in sector $h$ (which increases) and the wage in sector $m$ (which remains unchanged).

${ }^{16}$ For simplicity, we assume, that within a household, consumption and leisure of all household members are aggregated before they enter the joint utility function.

${ }^{17}$ To keep things simple, we assume that there are no unemployment benefits. Unemployed households live on their home production.
} 
Maximizing utility (9) subject to the constraints (10) through (12) yields

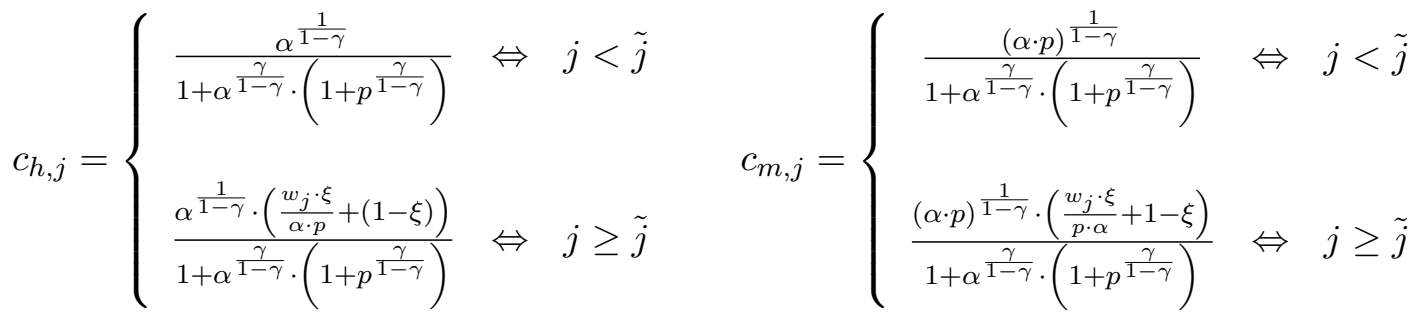

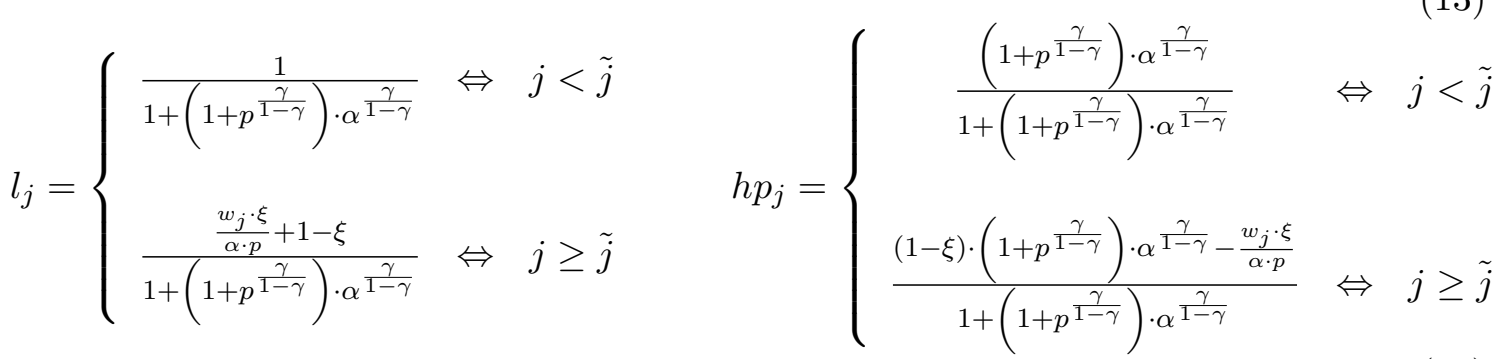

Consumption of good $h(m)$ is decreasing (increasing) in the relative goods price. Leisure is also decreasing in the relative price of the home-producible good $h$. The higher the price for good $h$, the higher is the opportunity cost of leisure because time can also be used to produce good $h$. Home production time is increasing in the relative price (of the home-producible good $h$ ). The implications of an increase in market work for home production and outsourcing are summarized in Lemma 2:

Lemma 2 At a given goods price $p$, an increase in retirement age $\rho$, labor force participation $\lambda$, or working time $\omega$ leads to a decrease in home production, $h p_{j}$, and an increase in outsourcing, os ${ }_{j}=c_{h, j}-h p_{j}$.

$$
\left.\frac{\partial h p_{j}}{\partial \xi}\right|_{\partial p=0}<0,\left.\quad \frac{\partial o s_{j}}{\partial \xi}\right|_{\partial p=0}>0 \text { where } \xi=\rho \cdot \lambda \cdot \omega .
$$

\subsection{General equilibrium}

In the following, we assume that the parameter constellation is such that (i) production in both sectors is strictly positive, (ii) unemployment is strictly positive and strictly below $100 \%$, and (iii) all types of households spend some strictly positive amount of time on home production.

Definition 1 An equilibrium corresponds to a price system $\left\{\left\{w_{j}\right\}_{j \in[0,1]},\left\{p_{i}\right\}_{i=h, m}\right\}$ and an allocation $\left\{\left\{c_{i j}\right\}_{j \in[0,1], i=h, m},\left\{l_{j}\right\}_{j \in[0,1]},\left\{h p_{j}\right\}_{j \in[0,1]},\left\{y_{i}\right\}_{i=h, m},\left\{y_{1, j}^{h p}\right\}_{j \in[0,1]}\right\}$ that satisfy the following conditions:

- (Utility Maximization): Given the price system $\left\{\left\{w_{j}\right\}_{j \in[0,1]},\left\{p_{i}\right\}_{i=h, m}\right\}$, the strategy $\left\{\left\{c_{i j}\right\}_{i=h, m}, l_{j}, h p_{j}\right\}$ maximizes the utility (9) of each household of type $j \in[0,1]$ 
under the technological constraint (10), and the respective budget and time constraints (11) or (12).

- (Profit Maximization): Given the price system $\left\{\left\{w_{j}\right\}_{j \in[0,1]},\left\{p_{i}\right\}_{i=h, m}\right\}$, the production plan $\left\{\left\{n_{i, j}\right\}_{j \in[0,1]}, y_{i}\right\}$ maximizes profits (2) of each firm in sector $i$.

- (Market Clearing):

For each consumer good $i=h, m: \quad \int_{0}^{1} c_{i, j} \cdot d j=y_{i}$.

For each production factor $j \in[0,1]: \quad \sum_{i=h}^{m} n_{i, j}=\xi$.

Proposition 1 Under assumptions (i), (ii), and (iii), an equilibrium exists and is unique. The relative goods' price $p$ as a function of technology parameters $\alpha$, $\chi$, preference parameter $\gamma$, institutional parameter $\theta$, labor force participation $\lambda$, retirement age $\rho$, and working time $\omega$ is given implicitly by

$$
(\alpha \cdot p)^{\frac{\gamma}{1-\gamma}} \cdot \frac{\alpha \cdot p \cdot \ln \left(\frac{\theta}{1+\theta} \cdot \frac{\chi \cdot p^{\frac{1+\chi}{\chi}}+e^{1+\chi}}{p \cdot(1+\chi)}\right)+\frac{\chi \cdot p^{\frac{1+\chi}{\chi}}+e^{1+\chi}}{(1+\theta) \cdot(1+\chi)}+\frac{1-\xi}{\xi} \cdot \alpha \cdot p}{1+\left(1+p^{\frac{\gamma}{1-\gamma}}\right) \cdot \alpha^{\frac{\gamma}{1-\gamma}}}=\frac{e^{1+\chi}-p^{\frac{1+\chi}{\chi}}}{1+\chi}
$$

where $\xi=\rho \cdot \lambda \cdot \omega$.

Proof. See Appendix 5.1.1.

Proposition 2 An increase in retirement age $\rho$, labor force participation $\lambda$, or working time $\omega$ leads to an increase in the relative goods price $p$ :

$$
\frac{\partial p}{\partial \rho}>0 \quad \frac{\partial p}{\partial \lambda}>0 \quad \frac{\partial p}{\partial \omega}>0
$$

Proof. See Appendix 5.1.2.

Increases in retirement age, labor force participation and working time all imply a rise in market work. An increase in market work makes households reduce home production and demand more of good $h$ from the market. As a consequence, the relative price of good $h$ rises.

From Lemma 1 we know that unemployment $\tilde{j}$ depends on the relative goods price $p$. This is the channel through which market work $\xi$ affects unemployment.

Proposition 3 An increase in retirement age $\rho$, labor force participation $\lambda$, or working time $\omega$ leads to a decrease in the unemployment rate $\tilde{j}$. This effect-in terms of $\frac{\partial \tilde{j}}{\partial \xi} \cdot \frac{\xi}{\tilde{j}}-$ is stronger the smaller is the elasticity of substitution between consumption and leisure $\sigma=\frac{1}{1-\gamma}$. 
Proof. See Appendix 5.1.3.

As stated in Proposition 2, an increase in market work leads to an increase in the relative price of good $h$. This shifts relative demand for lower types (in which the production of good $h$ is intensive) upward. This lifts the wages of some hitherto unemployed types above the minimum wage. They find employment and unemployment falls.

What is the role of the substitution elasticity in this effect? If substitutability is high, an increase in market work can easily be offset by a respective decrease in home production without the need for drastic changes in goods and factor prices. In this case, the wage rigidity does only little harm. In the extreme case of perfect substitutes, the relative goods price is equal to 1 and the unemployment rate is $\tilde{j}=\ln \left(\frac{\theta}{1+\theta} \cdot \frac{\chi+e^{1+\chi}}{1+\chi}\right)$ independently of market work $\xi$. If on the contrary substitutability is low, substantial changes in relative goods and factor prices are required to induce changes in consumption and leisure following an increase in market work. In this case, the wage rigidity has larger effects.

In summary, our general equilibrium model introduces a new argument into the old debate about the lump of labor fallacy. It is known that higher labor supply leads to more production, higher incomes and thereby higher demand for goods and labor. Our theoretical model shows that this increase in the demand for goods and services asymmetrically favors the demand for those goods and services whose production is intensive in the use of unskilled labor. In consequence, while the induced increase in labor supply is symmetric across all skill levels, the increase in labor demand is biased towards unskilled labor. Given the concentration of unemployment at unskilled labor, this shift in relative labor demand has positive employment effects.

\section{The empirical analysis}

In this section, we present evidence supporting our theory that increased market work goes along with less home production, more outsourcing of household work and other self-producible goods and lower unemployment. Our empirical evidence is organized as summarized in Figure 3: Firstly, we investigate the allocation of time by household members conditional on their working time (Section 3.3). We present direct evidence that less time is spent on home production activities the more time the household members spend on market work. In order to see whether home production is substituted by respective market goods and services, we secondly investigate data on help received by the household, comprising household services, child care, care for elderly persons and technical help (Section 3.4). This approach yields empirical evidence supporting our prediction that (a) households with a higher labor market participation reduce their time spent on home production, and (b) that they substitute these tasks by outsourcing, i.e., demanding services and products that fulfill these tasks.

In Sections 3.3 and 3.4, we consider two margins of labor market participation, namely 
changes in (weekly) working time and changes in labor force participation, particularly of women. The effects of a prolonged working life are not analyzed. There are some recent papers trying to explain the significant drop in consumer expenditures upon retirement which also investigate whether these households substitute home production for some goods and services formerly purchased at the market (Hamermesh 1984; Banks, Blundell, and Tanner 1998; Hurd and Rohwedder 2003; Aguiar and Hurst 2005; Heathcote 2002). Given the particular circumstances and needs of older (retired) people, the link between the length of working life and home production is studied separately in Lührmann (2006).

The third mechanism of our model, that this increased outsourcing of home production raises the demand for unskilled labor and reduces unemployment, cannot be analyzed using the same data set, since there is no matching information on sectoral production functions. Instead, we use macroeconomic data on OECD countries and directly estimate the reduced form relation between measures of labor supply and the unemployment rate (Section 3.5). We find that average working hours as well as the participation rate are negatively linked with the unemployment rate in these countries.

Figure 3: Overview over the empirical analysis

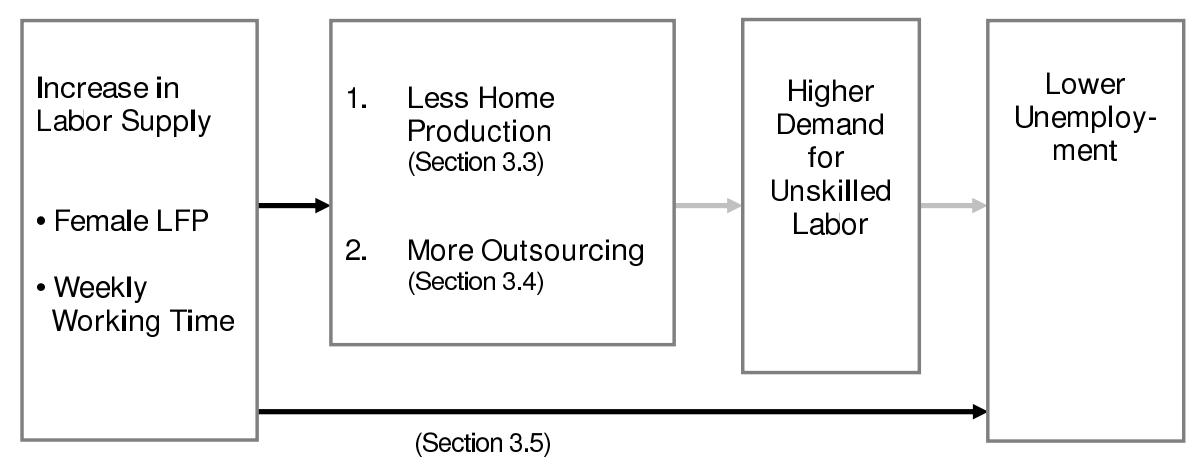

\subsection{The time use data}

First, we use the German time budget survey (Zeitbudgeterhebung) from 1991/92 by the Statistisches Bundesamt. We restrict the sample to West German households headed by married or cohabiting couples in the working age group 20-60. ${ }^{18}$ Since only one wave of the data is available, we conduct a cross sectional analysis. This implies that we cannot account for unobserved heterogeneity. However, we can filter many dimensions of inter-personal heterogeneity, because the survey contains a detailed set of household and personal characteristics as well as regional characteristics.

The time use of each respondent is surveyed for two days. The respondents fill in a time diary, which gives us the information on the total time spent on each activity during a day. We follow the standard classification scheme to group activities into home

\footnotetext{
${ }^{18}$ We exclude East German households, because they had very different labor market dynamics directly after the reunification in 1991/92. We use the provided sampling weights.
} 
production, working time and leisure time. The dependent variable home production, $h p$, is characterized as time spent for food preparation and cleanup, cleaning inside or outside the home, caring for clothes, plants and animals, time spent for shopping, home and car repair, and all children-related activities or caring for other people. Our working time variable, denoted $\omega$, is time spent working, commuting to work, taking breaks while at work, and searching for work. ${ }^{19}$ The distribution of working hours among the working by sex is shown in Figure 4. For men, it is distinctly single-peaked around 9-10 hours per day which corresponds to a full time job plus travel time etc. On the contrary, we see a very different distribution of female working time with two peaks. The first and highest peak is around 5 hours a day which accords with a part time job. The second and lower peak is again around 9-10 hours per day.

Figure 4: Distribution of mean work hours per day by sex among the working

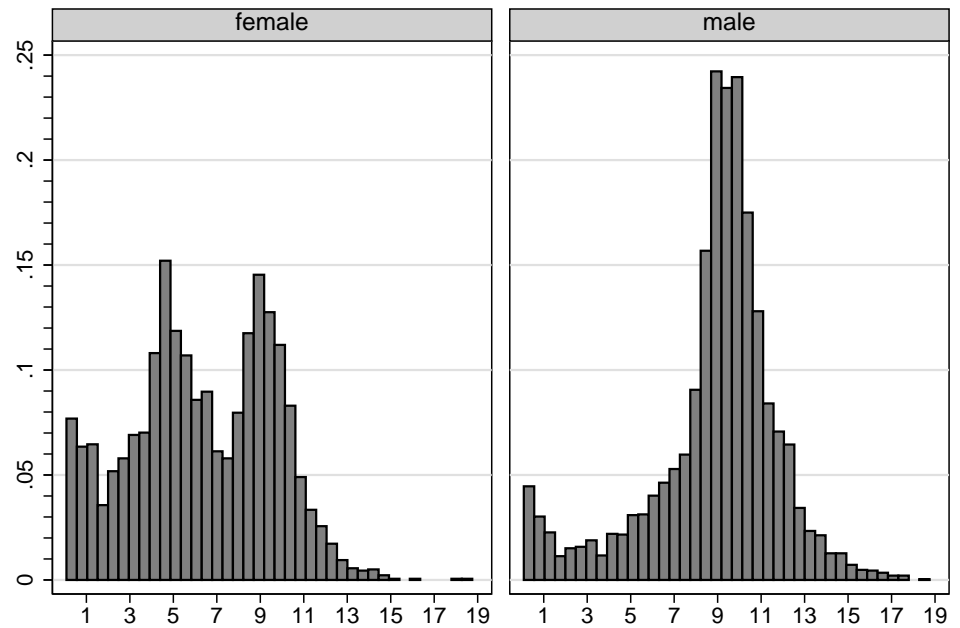

\subsection{A descriptive look at market work, home production, outsourcing and the demand for unskilled labor}

Since the German Time Use Survey has not been widely used by economists, we start with a descriptive overview of the time allocation by sex and employment status. We distinguish between women and men for two reasons: First, it is widely documented in the literature (Beblo 1999; Van der Lippe, Tijdens, and De Ruijter 2004) that men and women differ in their engagement in home production activities. Second, in contrast to males, females exhibit a very heterogenous labor market participation, and policies aimed at increasing labor force participation are often targeted at women.

General time use is split into three broad categories: Both, men and women, spend

\footnotetext{
${ }^{19}$ The last category, leisure, comprises time spent for sleeping and napping, washing, dressing, eating, receiving medical care, and time spent for everything else.
} 
Table 1: Time use by sex (in \% of total time)

\begin{tabular}{l|c|c|c}
\hline & market work & leisure & home production \\
& (incl. breaks, commuting, job search) & (incl. recreation, vol. work) & \\
\hline \multirow{2}{*}{ men } & 24.6 & 64.0 & 11.4 \\
women & 8.4 & 65.6 & 26.0 \\
\hline
\end{tabular}

about two thirds of their day on leisure activities as defined in Section 3.1. However, they differ substantially in how they spent the remaining time. While men spent 24.6 percent of their total time on work-related activities and 11.4 percent on home production activities on average, women allocate their time in the opposite manner (Table 1$).{ }^{20}$

Next, we decompose time use by employment status. Two things are worth noting from Table 2: (1) Working men and women spent less than half as much time on home production activities than their not working counterparts. (2) Differential work status does not explain the gender differences in home production time.

Table 2: Average home production by sex and employment status in hours per day (resp. $\%$ of total time)

\begin{tabular}{l|c|c|ccc}
\hline & all & not working & \multicolumn{3}{c}{ working } \\
& & & all & part time & fulltime \\
\hline \multirow{2}{*}{ men } & $2: 46(11.5 \%)$ & $4: 14(17.7 \%)$ & $1: 42(7.1 \%)$ & $3: 17(13.7 \%)$ & $1: 22(5.7 \%)$ \\
women & $6: 11(25.7 \%)$ & $7: 01(29.2 \%)$ & $4: 23(11.1 \%)$ & $5: 50(24.3 \%)$ & $1: 33(6.5 \%)$ \\
\hline
\end{tabular}

Decomposing time use by working time shows that women with a part time job spend about an hour and 10 minutes less time on home production per day than not working women, while full time employed women spend 5 and a half hours per day less on home production (Table 2). Figure 5 illustrates this strong and negative relation between home production and working time which is stronger for women. Even among men, the differences in home production by work status and hours are sizeable: Not working men take care of the household about 4 hours and a quarter each day while full time employed men only spend about an hour and 22 minutes on home production.

Next, we look at the relation between market work and outsourcing. We have information on whether a household receives help from outside the household, and if so, how much. Received help is classified in four categories, namely (1) help in the household (cleaning, shopping, laundry), (2) child care, (3) care for elderly persons, and (4) technical help. We summarize these four categories into one. $18.2 \%$ of all households under consideration answered that they receive help from outside the household. $7.6 \%$ of all households received help that was paid for.

\footnotetext{
${ }^{20}$ Brines (1994) and Greenstein (2000) put forward sociological factors to explain these gender differences. Beblo (1999) analyzes strategic behavior in intra-family time allocation.
} 
Figure 5: Home production by sex and hours of work

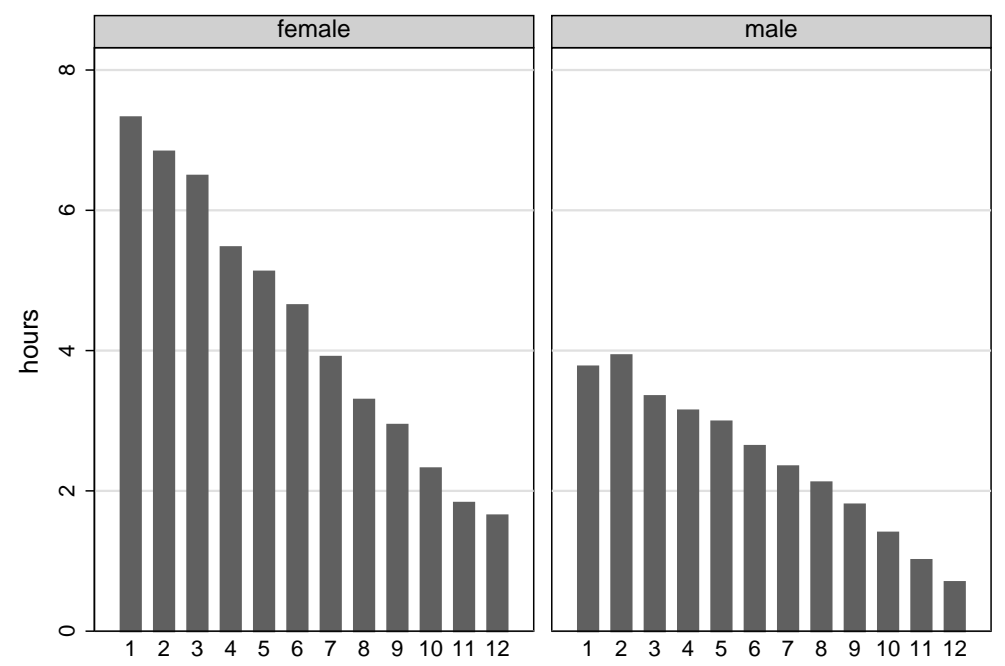

Table 3: Share of households receiving help, by employment status

\begin{tabular}{l|cccc}
\hline & & \multicolumn{3}{c}{ Households members are... } \\
Type of received help & all & both not employed & one employed & both employed \\
\hline unpaid & $11.6 \%$ & $0.0 \%$ & $7.1 \%$ & $14.6 \%$ \\
paid & $7.6 \%$ & $2.3 \%$ & $3.9 \%$ & $10.0 \%$ \\
unpaid and paid & $18.2 \%$ & $2.3 \%$ & $10.5 \%$ & $23.3 \%$ \\
\hline
\end{tabular}

Table 3 furthermore illustrates, that the higher a household's labor market participation, the higher is the probability that this household receives (unpaid and paid) help from outside. Using the German Socio-Economic Panel, Hank (2001) presents similar numbers and states that "dual career households use professional help the most." The fraction of households purchasing domestic services is highest among households in which women spend many hours in market work.

\subsection{Does increased market work lead to a reduction of home production?}

The goal of this section is to investigate the relationship between labor market participation and home production - as described in Lemma 2-in a multivariate setting. In our model, households maximize their utility from consumption and leisure as specified in equation (9). Producing goods and services at home saves money, but consumes time resources that could be spent on leisure activities. Hence, households will have to weigh the marginal cost of purchasing certain goods or services against the marginal cost of producing them at home. 
We model the decision how much time a household $j$ spends on home production per day as a function of household characteristics $Z$, work characteristics $\lambda, \omega$ and $\eta$ (defined below), monthly household net income Inc and its interactions with labor force participation, and individual characteristics of the spouses $X$. Furthermore, we control for seasonal and weekly patterns $T$ and regional factors $R$.

The key work characteristics are minutes of market work by husband and wife $\omega$, as measured on a diary day. We differentiate market work by husband and wife, because - given the descriptive evidence from Section 3.2 - we do not suppose that male and female market work are perfect substitutes. ${ }^{21}$ Since we have separate information about general labor force participation $\lambda$, and whether a person works on the specific day, at which home production is recorded, we can at least partially control for inter-temporal substitution of home production within a week. Hence, we include not only $\lambda$, but also a dummy taking the value 1 if a person is generally employed but does not work on the diary day which we denote as $\eta$.

The monthly income variable has been constructed from the individual net monthly incomes of husband and wife which are given in income brackets in the survey. We construct a continuous household income variable by estimating an ordered probit model with known cut points for the individual incomes and adding them up afterwards. This method and its implications are discussed in Appendix 5.3. For a description of the other variables used in the analysis see Appendix 5.2.

The empirical specification is the following: ${ }^{22}$

$$
\begin{aligned}
h p_{j}=\alpha & +\sum_{s}\left(\beta_{s}^{\lambda} \cdot \lambda_{s, j}+\beta_{s}^{\eta} \cdot \eta_{s, j}+\beta_{s}^{\omega} \cdot \omega_{s, j}\right)+\left(\gamma+\sum_{s} \gamma_{s}^{\lambda} \cdot \lambda_{s, j}\right) \cdot \operatorname{Inc}_{j} \\
& +\beta^{Z} \cdot Z_{j}+\sum_{s} \beta_{s}^{X} \cdot X_{s, j}+\beta^{T} \cdot T_{j}+\beta^{R} \cdot R_{j}+\epsilon_{j}
\end{aligned}
$$

where $h p$ denotes total time per day spent on home production at day $t$ in minutes. The subscripts stand for household $j$ and household member $s$ where $s$ can be the husband $m$ or the wife $f$. With this model, we can investigate whether there is empirical support for our theoretical predictions from Lemma 2 , that $\left.\frac{\partial h p_{j}}{\partial \xi}\right|_{\partial p=0}<0$, where $\xi=\rho \cdot \lambda \cdot \omega \cdot{ }^{23}$

Estimating equation 18 to evaluate our argument that the higher the household's labor supply, the less time will be spent on home production, gives the results depicted in Table 4. Column 1 shows a significant coefficient of male and female working time, $\omega$. As expected from Lemma 2, the more the household members work, the less time is spent on home production. For example, if the wife works one hour more, home production time of the household is reduced by 27 minutes. The magnitude of the effect is almost

\footnotetext{
${ }^{21}$ We include a participation dummy only for women, since there is almost no variation in male participation in the data.

${ }^{22}$ We omit the time subscript $t$ denoting the diary day for ease of notation.

${ }^{23}$ The partial equilibrium perspective $(\partial p=0)$ is taken here because - unlike in the theoretical model where $\lambda, \omega$, and $\rho$ are taken to be equal across all individuals - a change in individual labor force participation or working time does not have any (general equilibrium) effects on the relative goods price $p$.
} 
Table 4: Regression results

\begin{tabular}{|c|c|c|c|c|c|c|}
\hline \multicolumn{7}{|c|}{ dependent variable: total household home production } \\
\hline \multirow[b]{4}{*}{$\omega_{f}$} & \multirow{2}{*}{\multicolumn{2}{|c|}{$\begin{array}{l}\text { all } \\
(1)\end{array}$}} & \multirow{2}{*}{\multicolumn{2}{|c|}{$\begin{array}{l}\text { w/o kids } \\
(2)\end{array}$}} & \multirow{2}{*}{\multicolumn{2}{|c|}{$\begin{array}{l}\text { w/ kids } \\
(3)\end{array}$}} \\
\hline & & & & & & \\
\hline & \multicolumn{6}{|c|}{ participation and minutes of work } \\
\hline & -0.449 & $(-16.84)^{* * *}$ & -0.38 & $(-7.49)^{* * *}$ & -0.478 & $(-13.72)^{* * *}$ \\
\hline$\omega_{m}$ & -0.256 & $(-13.31)^{* * *}$ & -0.206 & $(-5.28)^{* * *}$ & -0.299 & $(-13.36)^{* * *}$ \\
\hline$\lambda_{f}$ & 55.237 & $(1.82)^{*}$ & 101.306 & $(1.55)$ & 31.989 & $(0.91)$ \\
\hline$\eta_{f}$ & -5.02 & $(-0.40)$ & 0.431 & $(0.02)$ & -1.26 & $(-0.09)$ \\
\hline \multirow[t]{2}{*}{$\eta_{m}$} & -3.373 & $(-0.30)$ & 15.484 & $(0.65)$ & -16.535 & $(-1.27)$ \\
\hline & \multicolumn{6}{|c|}{ household characteristics } \\
\hline Inc & 0.019 & $(1.78)^{*}$ & 0.037 & $(1.54)$ & 0.008 & $(0.66)$ \\
\hline $\operatorname{Inc} c^{2}$ & $-1.62 \mathrm{E}-06$ & $(-1.85)^{*}$ & $-3.15 \mathrm{E}-06$ & $(-1.63)$ & $-6.33 \mathrm{E}-07$ & $(-0.65)$ \\
\hline $\operatorname{Inc} * \lambda_{f}$ & -0.024 & $(-2.16)^{* *}$ & -0.043 & $(-1.76)^{*}$ & -0.014 & $(-1.12)$ \\
\hline$I n c^{2} * \lambda_{f}$ & $1.55 \mathrm{E}-06$ & $(1.75)^{*}$ & $3.12 \mathrm{E}-06$ & $(1.61)$ & $6.05 \mathrm{E}-07$ & $(0.60)$ \\
\hline$K i d s 0-5$ & 114.540 & $(21.35)^{* * *}$ & & & 87.643 & $(14.14)^{* * *}$ \\
\hline$K i d s 6-18$ & 27.340 & $(7.76)^{* * *}$ & & & 16.762 & $(3.64)^{* * *}$ \\
\hline$A g e_{A v g}$ & -0.332 & $(-0.79)$ & 1.34 & $(1.83)^{*}$ & -2.384 & $(-3.56)^{* * *}$ \\
\hline$A g e_{D i f f}$ & 1.31 & $(1.70)^{*}$ & -0.564 & $(-0.35)$ & 2.922 & $(3.25)^{* * *}$ \\
\hline SchoolYrs $_{A v g}$ & -5.297 & $(-1.85)^{*}$ & -3.528 & $(-0.57)$ & -4.093 & $(-1.26)$ \\
\hline \multirow[t]{2}{*}{ SchoolYrs $_{\text {Diff }}$} & 1.583 & $(0.72)$ & -8.844 & $(-1.67)^{*}$ & 6.403 & $(2.74)^{* * *}$ \\
\hline & \multicolumn{6}{|c|}{ living conditions of the household } \\
\hline AppSize & 0.079 & $(0.76)$ & 0.526 & $(2.11)^{* *}$ & -0.081 & $(-0.73)$ \\
\hline AppOwner & 17.346 & $(1.38)$ & 7.314 & $(0.28)$ & 25.068 & $(1.71)^{*}$ \\
\hline HOwner & 41.777 & $(4.92)^{* * *}$ & 51.261 & $(2.80)^{* * *}$ & 26.847 & $(2.80)^{* * *}$ \\
\hline Garden & 32.596 & $(3.99)^{* * *}$ & 30.152 & $(1.84)^{*}$ & 41.967 & $(4.36)^{* * *}$ \\
\hline Constant & 634.683 & $(9.94)^{* * *}$ & 302.801 & $(2.20)^{* *}$ & 842.761 & $(11.68)^{* * *}$ \\
\hline Obs. & 4304 & & 941 & & 3363 & \\
\hline$A d j . R^{2}$ & 0.42 & & 0.34 & & 0.38 & \\
\hline
\end{tabular}

Note: t statistics in parentheses. ${ }^{*}, * *, * * *$ denote significance at $10 \%, 5 \%, 1 \%$.

Additional regressors (not reported here): regional (Southern and Central Germany), seasonal and weekday dummies, and regional characteristics like unemployment rates, gross national product, urbanization and the size of the tertiary sector. 
twice as high compared to male working time. A t-test reveals that the difference between the two coefficients is statistically significantly different from zero. Female labor force participation $\lambda_{f}$ during the week is weakly positively significant in specification (1), as are its interactions with income and income squared. However, we cannot reject the hypothesis of a joint difference from zero using an F-test $(F(3,4269)=1.98)$. We also do not find evidence of inter-temporal substitution of home production over the week, i.e., we see no empirical evidence that employed household members do more home production on their "free" days during the week. The overall effect of these three participation measures is significantly negative, as will be shown below in Table 5 .

One might argue that the supply or availability of child care might affect the labor supply decision, rendering it endogenous. We deal with this endogeneity by including in all specifications - three broadly defined region dummies and four variables capturing local unemployment rate, regional GNP per capita, the degree of urbanization, and the size of the tertiary sector on a finer regional level. These regional characteristics are likely correlated with the degree of availability of child care, as it is part of the tertiary sector, varies by population density and urbanization of the area, and so forth. Hence, we use them as proxies for the availability of child care and domestic services. None of these regional variables has a significant impact on home production.

A second objection might be that there is a potential simultaneity of the work and the home production choice which biases our OLS results: namely, that the labor supply decision affects the household's demand for child care, and vice versa. As a robustness check, we split the sample into couples with and without children, because we suppose that an endogeneity bias will be present mainly with regard to child care availability. Women might decide to start working again when they can easily source out child care, i.e., when the grandparents live close by or when professional child care is easily available. Hence, childless couples should be affected to a much lesser extent. We find a slightly lower impact of working time on home production in childless households (column 2) —about 7 minutes difference compared to results from (1) - but the differences are not substantial.

Furthermore, we use the fact that we observe each person's time use over two diary days in order to estimate a fixed effect model which allows us to filter unobserved heterogeneity like tastes for work and also the availability of home production substitutes. The results are very similar to those shown in Table 4 and are contained in Appendix 5.4.

The total effect of female labor supply (including participation and working time) on a household's home production is shown in Table 5. The table displays the difference in household home production time between a not working and a working woman. Increases in market work imply accompanying pay raises which also affect home production time and the amount of outsourcing. We take this into account using the differences in the conditional mean incomes of households with full (part) time working women and those with not working women in our sample. Furthermore, we assume an average hourly net 
wage of $18.40 \mathrm{DM}^{24}$ We determine working time in a part- or full-time job from the distribution of female working hours. Part-time is roughly defined as the lower peak value at 5 hours per day, full-time as the higher peak value at 9.5 hours (see Figure 4).

Table 5: Net effect of female labor market participation on household home production time (in hours per day)

\begin{tabular}{|c|c|c|c|}
\hline & $\begin{array}{l}\text { not working woma } \\
\text {..ppart time }\end{array}$ & $\begin{array}{l}\text { woman working } \\
\text {...full time }\end{array}$ & $\begin{array}{l}\text { woman working } \\
1 \mathrm{~h} \text { more }\end{array}$ \\
\hline home production time & $-1: 23 \quad(-2.89)^{* * *}$ & $-3: 28 \quad(-7.13)^{* * *}$ & $-0: 27 \quad(-13.85)^{* * *}$ \\
\hline
\end{tabular}

The first (resp. second) column contains the difference in home production time between a household with a not working woman and one with a part (resp. full) time working woman: it amounts to a considerable one hour and 23 minutes respectively three and a half hours per day. In the third column, we calculate the effect of one additional work hour which reduces the home production time of the household by 27 minutes. Thus, female market work results in a statistically significant reduction in home production time. The reduction is larger, the more hours a woman works.

Hence, our findings suggest that: (1) The more the spouses work, the less time is spent on home production in the household. (2) This effect is almost double as large for women than for men, and it is sizeable: One additional hour in market work crowds out almost half an hour of household home production time.

Finally, we briefly comment on the results for the other household and personal characteristics: We cannot find evidence of a direct effect of education on home production time, that would be due to education-specific attitudes and tastes etc. We also do not find a strong relation between age and home production. We additionally include quarterly and weekday dummies into our estimation to capture seasonal effects in home production. For example, the positive significant coefficients for the second quarter suggest that households engage more actively in some outdoor home production tasks, e.g., repairing the house or doing some gardening. Furthermore, descriptive evidence suggests that significantly less home production is done on Sundays than during the week. This is probably due to the fact that no shopping can be done on Sundays and that the Sunday is still widely perceived as a leisure day and often reserved for family and social activities.

\subsection{Does more market work result in more outsourcing?}

In the preceding section, we analyzed the link between market work and the time spent on home production. We found that more time spent on market work is associated with

\footnotetext{
${ }^{24}$ This number is computed from the IAB-Beschäftigtenstichprobe 1992.
} 
less time spent on home production. In this section, we use the data on "help received by the household" described in Section 3.2 to study the link between market work of household members and the demand for these services. ${ }^{25}$ Lemma 2 makes the clear prediction that increased market work leads to more outsourcing of home-producible goods and services. The idea is that at least part of a household's home production can in principle be outsourced. Our measure "received" help does certainly not cover all components of outsourcing, e.g., it excludes child care outside households (kindergartens, nurseries, etc.), eating out, bringing clothes to the dry-cleaner, having them ironed and sewed and so forth. Furthermore, only $7.6 \%$ of our sample households report to have received paid help. This low percentage is most likely due to underreporting. In Germany, many household aids are employed without official registration, as this would imply the duty to pay social security contributions and taxes on both sides, employer and employee. ${ }^{26}$ For these two reasons, we regard our analysis as a very conservative lower bound of the impact of labor market participation on the demand for household services and the like.

We estimate the link between households' labor market participation and their demand for paid services that substitute for home production. We use the same specification as in equation 18, just substituting received help $r h$ for home production $h p$. Since only $7.6 \%$ of the households in our sample actually report to receive paid help, we observe a large fraction of zeros for the dependent variable. Simplifying equation 18 for illustrative purposes, we get: $r h_{j}^{*}=x_{j}^{\prime} \beta+\epsilon_{j}$ where the error term is normally distributed, $\epsilon_{j} \sim$ $N\left(0, \sigma^{2}\right)$, and $r h^{*} \mid x_{j} \sim N\left(\beta^{\prime} x_{j}, \sigma^{2}\right)$. The censored variable can be characterized as:

$$
r h=\left\{\begin{array}{l}
r h^{*} \text { if } r h^{*}>0 \\
0 \text { else }
\end{array}\right.
$$

The probability of observing positive outsourcing is: $P(r h>0)=P\left(r h^{*}>0\right)=\Phi\left(\frac{\beta^{\prime} x_{j}}{\sigma}\right)$. Hence, the Likelihood for the censored regression model is:

$$
L=\prod_{j=0}^{n}\left[\Phi\left(\frac{x_{j}^{\prime} \beta}{\sigma}\right)\right]^{-1} \cdot \frac{1}{\sigma} \cdot \phi\left(\frac{r h_{j}-x_{j}^{\prime} \beta}{\sigma}\right)
$$

Table 7 reports the regression results of this censored Tobit model. ${ }^{27}$ The estimated coefficients on women's labor force participation and working time of women (in minutes per day) are both significant and positive. The coefficient for men's working time is about

\footnotetext{
${ }^{25}$ Throughout this section, we aggregate the four categories of received help under the label "outsourcing".

${ }^{26}$ According to Brück, Haisken-DeNew, and Zimmermann (2003),pp.4, there are about 40.000 officially registered employees in the household sector in Germany. Estimates, on the contrary, point to about 500.000 employees in the domestic service sector.

${ }^{27}$ As a further robustness check, we also estimated a Heckman selection model and got very similar results. Our identifying assumptions were that labor force participation only affects the decision of whether or not to hire a home help while working time only affects the extent to which a home help is engaged. Other variables that entered only the selection equation were urbanization of the place of residence, regional GNP per capita, and the size of the regional service sector. These latter variables affect the regional availability of household services.
} 
as large. As expected from Lemma 2, the more the household members work, the more household activities are outsourced. Again, we exclude men's labor force participation for lack of variation in that variable. Income and the number of children aged 0 to 5 positively affect the amount of paid help. Other significant control variables are education, urbanization of the place of residence, and regional GNP per capita. The sample size prohibits the sample split into households with and without children done in Section 3.3. In order to get an idea of the magnitude of these effects, we calculate the impact of changes in female market work on purchased hours of home help (Table 6). We use the same computation method as in Section 3.3. The first (second) column displays the effect on the outsourcing of housework when the woman enters the labor market and works part (full) time. The overall effect is an increase by roughly one hour per week, or $+263 \%$, in the case of a switch towards a part time job. The effect of taking up a full time job is slightly smaller. This unexpected result arises because outsourcing is a hump-shaped function of women's working time. The hump's peak is between 5 and 6.5 working hours per day. This finding is robust with respect to different specifications (polynomials of different order, splines). An increase in the woman's daily working time by one hour raises the household's outsourcing by 12 minutes per week (+18\%) (third column). In absolute terms, the effects may seem small. However, the numbers represent averages over the whole sample of which $92.4 \%$ do not make use of any paid help at all. Furthermore, our data contain only a fraction of tasks that could possibly be outsourced. For example, we do not have information on outsourcing of food preparation (going to restaurants, pizza service), drinks delivery, cleaning and ironing of clothes, kindergartens, nurseries, and other services that are rendered outside the household.

Table 6: Net Effect of Female Labor Market Participation on Help Received (in minutes per week)

\begin{tabular}{|c|c|c|c|}
\hline change in received help & $\begin{array}{l}\text { woman swit } \\
\text {...part time }\end{array}$ & $\begin{array}{l}\text { from not working to working } \\
\text {...full time }\end{array}$ & $\begin{array}{l}\text { woman works } \\
1 \mathrm{~h} \text { more }\end{array}$ \\
\hline absolute & $+66: 44$ & $+66: 02$ & $+11: 47$ \\
\hline relative & $+263 \%$ & $+260 \%$ & $+18 \%$ \\
\hline
\end{tabular}

In summary, these results strongly corroborate the theoretical predictions from Section 2. An increase in market work implies that households have less time and more money. The increase in income can be expected to entail a roughly proportional increase in total expenditures. But this increase is not proportional across different goods. Household income (and thus total consumer expenditures) increases by roughly one third, when the woman takes up a full-time job. At the same time, the demand for household services and other types of paid help rises by more than $260 \%$. As these services are mostly rendered by unskilled workers, the relative demand for unskilled labor increases in the wake of increases in working time or labor force participation. 
Table 7: Regression Results

\begin{tabular}{|c|c|c|}
\hline \multicolumn{3}{|c|}{ dependent variable: paid help received by the household (in minutes per day) } \\
\hline \multirow[b]{2}{*}{$\lambda_{f}$} & \multicolumn{2}{|c|}{ participation and minutes of work } \\
\hline & 64.57 & $(4.12)^{* * *}$ \\
\hline$\omega_{f}$ & 0.2226 & $(2.48)^{* *}$ \\
\hline$\omega_{f}^{2}$ & -0.0003191 & $(-2.15)^{* *}$ \\
\hline$\omega_{m}$ & 0.1663 & $(2.16)^{* *}$ \\
\hline \multirow[t]{2}{*}{$\omega_{m}^{2}$} & -0.0001385 & $(-1.43)$ \\
\hline & household characteristics & \\
\hline Inc & 0.03040 & $(2.49)^{* *}$ \\
\hline $\operatorname{Inc} c^{2}$ & $-3.43 \mathrm{e}-7$ & $(-0.39)$ \\
\hline Kids $0-5$ & 56.63 & $(6.27)^{* * *}$ \\
\hline Kids6-18 & 3.428 & $(0.58)$ \\
\hline$A g e_{A v g}$ & 0.6968 & $(1.52)$ \\
\hline SchoolYrs $s_{A v g}$ & 10.89 & $(3.71)^{* * *}$ \\
\hline \multirow[t]{2}{*}{ TrainYrs $_{\text {Avg }}$} & 7.007 & $(2.03)^{* *}$ \\
\hline & regional characteristics & \\
\hline Urban & 31.66 & $(3.38)^{* * *}$ \\
\hline$G N P$ & -0.002338 & $(-3.33)^{* * *}$ \\
\hline TertSec & 1.308 & $(1.55)$ \\
\hline Weekend & 50.80 & $(2.82)^{* * *}$ \\
\hline Constant & -890.6 & $(-9.69)^{* * *}$ \\
\hline Observations & 4392 (of which 338 unc & nsored, 4054 censored) \\
\hline
\end{tabular}

\subsection{Is there a link between labor market participation and unemploy- ment in the OECD?}

In the preceding sections, we looked at micro data and found that the empirical link between market work, home production and outsourcing behavior of households is in line with our theoretical model. In this section, we investigate whether the macroeconomic evidence is consistent with our predictions from Proposition 3. Hence, we directly look at the reduced form relation between labor supply and unemployment in 23 OECD countries between 1980 and 2003. ${ }^{28}$ Appendix 5.2 describes the coverage and sample statistics of the data.

Our theoretical model predicts that over time and across countries, higher degrees of labor market participation lead to lower unemployment. Labor market participation in our model encompasses a higher labor force participation, longer weekly work hours, or a prolonged work life, caused, e.g., by a higher retirement age. As data on average

\footnotetext{
${ }^{28}$ For Turkey, data on working hours are not available.
} 
retirement age are not available, we use the labor force participation of workers aged 55 to 64 years instead. Additionally, we use a set of control variables described below.

Potential endogeneity of the key variables can be present for various reasons. Unemployment and labor force participation both vary over the business cycle. Both increase in economic downturns. The counter-cyclicality of labor force participation has become known as the "added worker" effect: Women enter the labor market in recessions when their husbands' incomes decrease or when the husbands loose their jobs. This effect potentially biases our estimates towards zero. Therefore we include GDP growth in the regression to control for business cycle effects. Another source of endogeneity might be the belief of some governments that shorter working hours and early retirement schemes can be used as a cure against unemployment. If these policy measures are realized, then we expect shorter working hours and lower labor force participation (especially of the elderly) in countries and years, in which the unemployment problem is more severe. This would bias our estimates away from zero. Therefore, we control for country fixed effects that additionally control for time-invariant unobserved country heterogeneity. As a robustness check, we also used one-period lags of our regressors in the estimation. We take first differences of all variables in order to avoid problems of spurious correlation.

Another potential bias in our estimates arises if changes in working time affect unit labor costs, and thereby labor demand and (un)employment (see Footnote 3). In that case, unemployment and working hours are negatively related independently of the mechanisms of our model. In order to avoid this potential omitted variables bias, we also account for unit labor costs. As further control variables, we include an index of employment protection legislation and union density in order to capture time-variant institutional country differences that might affect unemployment rates. ${ }^{29}$

As the value of the dependent variable, the unemployment rate, must always lie within the unit interval, we use a logistic specification:

$$
U R=\frac{e^{\beta_{0}+\beta_{p} \cdot \lambda^{a l l}+\beta_{55} \cdot \lambda^{55+}+\beta_{h} \cdot \omega+\sum_{k} \gamma_{k} \cdot x_{k}}}{1+e^{\beta_{0}+\beta_{p} \cdot \lambda^{a l l}+\beta_{55} \cdot \lambda^{55+}+\beta_{h} \cdot \omega+\sum_{k} \gamma_{k} \cdot x_{k}}}
$$

where $U R$ is the unemployment rate, $\lambda^{\text {all }}$ is the rate of labor force participation in the entire population, $\lambda^{55+}$ is the participation rate of persons aged 55 to 64 years, $\omega$ are average yearly working hours, and $x_{k}$ denotes one of a set of $k$ additional regressors. In order to estimate this non-linear relation with linear estimation methods, we make the transformation:

$$
U R^{\text {logistic }}=\ln \left(\frac{U R}{1-U R}\right)=\beta_{0}+\beta_{p} \cdot \lambda^{\text {all }}+\beta_{o} \cdot \lambda^{55+}+\beta_{h} \cdot \omega+\sum_{k} \gamma_{k} \cdot x_{k} .
$$

\footnotetext{
${ }^{29}$ See Blanchard and Wolfers (2000) for a detailed discussion of the institutional determinants of unemployment rates in Europe.
} 
Table 8: Regression results

\begin{tabular}{|c|c|c|c|c|c|c|}
\hline & (1) & & $(2)$ & & $(3)$ & \\
\hline Participation (all) & -7.742 & $(-6.39)^{* * *}$ & -8.183 & $(-5.81)^{* * *}$ & -7.194 & $(-4.05)^{* * *}$ \\
\hline Participation (55-64 years) & -0.620 & $(-1.02)$ & -0.349 & $(-0.52)$ & -0.219 & $(-0.24)$ \\
\hline Working Hours & -12.990 & $(-3.53)^{* * *}$ & -8.835 & $(-2.35)^{* *}$ & -8.005 & $(-1.68)^{*}$ \\
\hline GDP growth p.c. & & & -0.339 & $(-0.93)$ & -0.580 & $(-1.20)$ \\
\hline Empl. Protection Legislation & & & 0.114 & $(1.07)$ & 0.055 & $(0.50)$ \\
\hline Union Density & & & 0.039 & $(4.90)^{* * *}$ & 0.049 & $(4.72)^{* * *}$ \\
\hline Unit Labor Cost & & & & & 0.004 & $(0.90)$ \\
\hline Constant & 0.009 & $(1.19)$ & 0.020 & $(2.33)^{* *}$ & 0.009 & $(0.94)$ \\
\hline No. Obs. (No. Countries) & 449 & $(23)$ & 354 & $(21)$ & 261 & $(19)$ \\
\hline Adj. $R^{2}$ & 0.08 & & 0.17 & & 0.14 & \\
\hline
\end{tabular}

Note: $\mathrm{t}$ statistics in parentheses. ${ }^{* *},{ }^{* *}$ denote significance at $5 \%, 1 \%$. All variables are in first differences. In all specifications, we estimate fixed-effects models.

Table 8 displays the regression results. We estimate three specifications: (1) contains the variables of interest only, and (2) additionally includes the described control variables per capita GDP growth, employment protection legislation, and union density rates. Column (3) additionally accounts for unit labor costs. We introduce unit labor costs in a separate specification, because it reduces our sample size quite substantially. All three columns show a significant link between total labor force participation and working hours and the unemployment rate. ${ }^{30}$ This is consistent with our theory. Labor force participation of older workers turns out insignificant. One explanation might be that many OECD countries have or had generous pre-retirement schemes in place such that at least those still participating beyond age 60 are a strongly selected group. ${ }^{31}$ If increases in the participation rates of the elderly arise from a tightening of social security systems, then this may induce less skilled and less wealthy people to work longer. If this is the case, then we do not expect substantial increases in outsourcing or sizeable reductions of the unemployment rate. We also conducted robustness checks using additional explanatory variables like the degree of wage inequality, and the replacement rate of unemployment benefits. Our results turn out to be robust with respect to these alternative specifications.

\footnotetext{
${ }^{30}$ The weak significance of working hours in the third specification is due to the sample reduction by more than a quarter.

${ }^{31}$ For example, those who did not spend many years on earning a degree or getting tertiary education, started their working life early and can retire earliest - at least in Germany.
} 


\section{Conclusions}

In this paper, we introduce a new argument into the debate about the employment effects of labor market policy measures targeted at increasing working time, retirement age, and labor force participation: We develop a general equilibrium model showing that positive employment effects for the unskilled can arise from general increases in labor supply.

The mechanism how these jobs might accrue works through the goods market. We argue that changes in individuals' labor supply entail changes in the composition of their consumer demand. Longer working hours and higher labor force participation imply that workers have higher incomes and less time for leisure and home production. As a consequence, home production decreases, and the demand composition shifts towards those goods and services that substitute for home production. As the goods and services that can be produced by everyone at home require few skills, the relative demand for unskilled labor rises. If the relative wage does not adjust perfectly to changes in relative labor demand, unemployment among the unskilled falls.

In the second part of the paper, we produce empirical evidence that corroborates our theoretical results. We use a time use survey conducted in West German households in 1991/92 to explore the main mechanisms of the model empirically: The link between labor supply and home production and the link between labor supply and outsourcing of household services and other home-producible goods and services. We find quantitatively relevant effects of labor force participation and work hours on both, time spent on home production by the household and outsourcing of these tasks among working age couples. One additional hour in market work of the woman crowds out 27 minutes of the household's home production per day. Accordingly, outsourcing rises by 12 minutes per week $(+18 \%)$. Switching from not working to working full time results in a reduction of home production time of about 3 and a half hours per day. As a consequence, outsourcing rises by more than one hour $(+260 \%)$. These effects imply that increases in market work can have large positive effects on the demand for unskilled labor.

At the macroeconomic level, we additionally investigated the link between labor market participation and unemployment rates directly. Controlling for some institutional determinants of unemployment rates, we find a strongly significant and negative relationship for 23 OECD countries from 1980 to 2003 . We take this as further evidence in favor of our model. 


\section{Appendix}

\subsection{Proofs}

\subsubsection{Proof of Proposition 1}

At $p=0$, the right hand side $(R H S)$ of equation (16) is larger than the left hand side $($ LHS $)$ :

$$
\frac{e^{1+\chi}}{1+\chi} \cdot \xi=R H S(0) \geq \operatorname{LHS}(0)=\left\{\begin{array}{cl}
0 & \Leftrightarrow \gamma>0 \\
\frac{1}{3} \cdot \frac{e^{1+\chi}}{(1+\theta) \cdot(1+\chi)} \cdot \xi & \Leftrightarrow \gamma=0 \\
\left.\frac{e^{1+\chi}}{(1+\theta) \cdot(1+\chi}\right) \cdot \xi & \Leftrightarrow \gamma<0
\end{array}\right.
$$

The limit of the right hand side for $p \rightarrow \infty$ is smaller than the limit of the left hand side:

$$
-\infty=\lim _{p \rightarrow \infty} R H S(p)<\lim _{p \rightarrow \infty} \operatorname{LHS}(p)=\infty
$$

Both sides of the equation are continuous in $p$. Therefore, at least one $p$ must exist that makes both sides equal. This establishes the existence of the general equilibrium.

As stated in Section 2.4, we only consider parameter constellations for which production in both sectors is strictly positive. This requires for the relative goods' price: $p \in\left[1, e^{\chi}\right]$. Within these limits, aggregate demand for good 2 is increasing in the relative price of good $1, p$, while aggregate supply of good 2 is decreasing in $p$. Thus, if an equilibrium price $p$ exists, it must be unique.

\subsubsection{Proof of Proposition 2}

The equilibrium condition is $C_{2}(p(\xi), \xi)=Y_{2}(p(\xi), \xi)$. Let $\eta_{u, v}=\frac{\partial u}{\partial v} \cdot \frac{v}{u}$ denote the relative effect of $u$ on $v$. Comparative statics with respect to $\xi$ yields:

$$
\eta_{p, \xi}=-\frac{\eta_{Y_{2}, \xi}-\eta_{C_{2}, \xi}}{\eta_{Y_{2}, p}-\eta_{C_{2}, p}}
$$

The denominator is negative (see the proof of uniqueness in Appendix 5.1.1). How about the numerator?

$$
\eta_{Y_{2}, \xi}=1 \quad \text { and } \quad \eta_{C_{2}, \xi}=1-\frac{\frac{(p \cdot \alpha)^{\frac{1}{1-\gamma}}}{1+\left(1+p^{\frac{\gamma}{1-\gamma}}\right) \cdot \alpha^{\frac{\gamma}{1-\gamma}}}}{C_{2}}
$$

so that

$$
\eta_{Y_{2}, \xi}-\eta_{C_{2}, \xi}=\frac{\frac{(p \cdot \alpha)^{\frac{1}{1-\gamma}}}{1+\left(1+p^{\frac{\gamma}{1-\gamma}}\right) \cdot \alpha^{\frac{\gamma}{1-\gamma}}}}{C_{2}}>0
$$

which implies that

$$
\eta_{p, \xi}=-\overbrace{<0}^{\frac{\overbrace{\eta_{Y_{2}, \xi}-\eta_{C_{2}, \xi}}^{>0}}{\underbrace{}_{\eta_{Y_{2}, p}-\eta_{C_{2}, p}}}}>0
$$




\subsubsection{Proof of Proposition 3}

From Lemma 1 we know that unemployment is decreasing with the relative goods price $p$. Together with Proposition 2 this implies that a reduction in market work $\xi$ leads to an increase in unemployment $\tilde{j}$.

Next, we have to show that the effect of market work $\xi$ on unemployment $\tilde{j}$ is stronger, the smaller is the elasticity of substitution between consumption and leisure $\sigma$ :

$$
\frac{\partial\left|\eta_{\tilde{j}, \xi}\right|}{\partial \sigma}<0 \Leftrightarrow \frac{\partial\left(\eta_{\tilde{j}, \xi}\right)}{\partial \sigma}>0
$$

Market work $\xi$ affects unemployment only through the relative goods price $p$ (see equation 8):

$$
\eta_{\tilde{j}, \xi}=\eta_{\tilde{j}, p} \cdot \eta_{p, \xi}
$$

The effect of the relative goods price $p$ on unemployment $\tilde{j}$ does not depend on the substitution elasticity $\sigma$ (see Lemma 1):

$$
\frac{\partial\left(\eta_{\tilde{j}, \xi}\right)}{\partial \sigma}=\underbrace{\frac{\partial\left(\eta_{\tilde{j}, p}\right)}{\partial \sigma}}_{=0} \cdot \underbrace{\eta_{p, \xi}}_{<0}+\underbrace{\eta_{\tilde{j}, p}}_{<0} \cdot \frac{\partial\left(\eta_{p, \xi}\right)}{\partial \sigma} \stackrel{?}{>} 0
$$

It suffices thus to show that $\frac{\partial\left(\eta_{p, \xi}\right)}{\partial \sigma}<0$.

$$
\frac{\partial\left(\eta_{p, \xi}\right)}{\partial \sigma}=-\frac{\frac{\partial\left(\eta_{Y_{2}, \xi}-\eta_{C_{2}, \xi}\right)}{\partial \sigma} \cdot\left(\eta_{Y_{2}, p}-\eta_{C_{2}, p}\right)-\left(\eta_{Y_{2}, \xi}-\eta_{C_{2}, \xi}\right) \cdot \frac{\partial\left(\eta_{Y_{2}, p}-\eta_{C_{2}, p}\right)}{\partial \sigma}}{\left(\eta_{Y_{2}, p}-\eta_{C_{2}, p}\right)^{2}} \stackrel{?}{<} 0
$$

From Appendix 5.1.2 we know that $\eta_{Y_{2}, p}-\eta_{C_{2}, p}<0, \eta_{Y_{2}, \xi}-\eta_{C_{2}, \xi}>0$ and that

$$
\eta_{Y_{2}, \xi}-\eta_{C_{2}, \xi}=\frac{\frac{(p \alpha)^{\frac{1}{1-\gamma}}}{1+\left(1+p^{\frac{\gamma}{1-\gamma}}\right) \alpha^{\frac{\gamma}{1-\gamma}}}}{C_{2}}=\frac{p \alpha}{\xi p \alpha \ln \left(\frac{\theta}{1+\theta} \frac{\chi p^{\frac{1+\chi}{\chi}}+e^{1+\chi}}{p(1+\chi)}\right)+\frac{\chi p^{\frac{1+\chi}{\chi}}+e^{1+\chi}}{(1+\theta)(1+\chi)} \xi+(1-\xi) p \alpha}
$$

independent of $\sigma=\frac{1}{1-\gamma}$. Therefore $\frac{\partial\left(\eta_{Y_{2}, \xi}-\eta_{C_{2}, \xi}\right)}{\partial \sigma}=0$.

All that remains to be shown is that $\frac{\partial\left(\eta_{Y_{2}, p}-\eta_{C_{2}, p}\right)}{\partial \sigma}<0$. From equation 6 follows that $\frac{\partial\left(\eta_{Y_{2}, p}\right)}{\partial \sigma}=0$.

$$
\eta_{C_{2}, p}=\frac{\partial\left(\frac{(p \cdot \alpha)^{\frac{\gamma}{1-\gamma}}}{1+\left(1+p^{\frac{\gamma}{1-\gamma}}\right) \cdot \alpha^{\frac{\gamma}{1-\gamma}}}\right)}{\partial p} \frac{p}{\frac{(p \cdot \alpha)^{\frac{\gamma}{1-\gamma}}}{1+\left(1+p^{\frac{\gamma}{1-\gamma}}\right) \cdot \alpha^{\frac{\gamma}{1-\gamma}}}}+\frac{\partial \Lambda}{\partial p} \frac{p}{\Lambda}
$$


where $\Lambda=\left(\xi \cdot p \cdot \alpha \cdot \ln \left(\frac{\theta}{1+\theta} \cdot \frac{\chi \cdot p^{\frac{1+\chi}{\chi}}+e^{1+\chi}}{p \cdot(1+\chi)}\right)+\frac{\chi \cdot p^{\frac{1+\chi}{\chi}}+e^{1+\chi}}{(1+\theta) \cdot(1+\chi)} \cdot \xi+(1-\xi) \cdot p \cdot \alpha\right)$ does not depend on $\gamma$.

$$
\frac{\partial\left(\frac{(p \cdot \alpha)^{\frac{\gamma}{1-\gamma}}}{1+\left(1+p^{\frac{\gamma}{1-\gamma}}\right) \cdot \alpha^{\frac{\gamma}{1-\gamma}}}\right)}{\partial p} \frac{p}{\frac{(p \cdot \alpha)^{\frac{\gamma}{1-\gamma}}}{1+\left(1+p^{\frac{\gamma}{1-\gamma}}\right) \cdot \alpha^{\frac{\gamma}{1-\gamma}}}}=\frac{\gamma}{1-\gamma} \cdot \frac{1+\alpha^{\frac{\gamma}{1-\gamma}}}{1+\left(1+p^{\frac{\gamma}{1-\gamma}}\right) \cdot \alpha^{\frac{\gamma}{1-\gamma}}}
$$

It suffices to show that

$$
\frac{\partial\left(\eta_{C_{2}, p}\right)}{\partial \sigma}=\frac{\partial\left(\frac{\gamma}{1-\gamma} \cdot \frac{1+\alpha^{\frac{\gamma}{1-\gamma}}}{1+\left(1+p^{\frac{\gamma}{1-\gamma}}\right) \cdot \alpha^{\frac{\gamma}{1-\gamma}}}\right)}{\partial \sigma}>0
$$

With $\frac{\gamma}{1-\gamma}=\sigma-1$ :

$$
\frac{\partial\left(\eta_{C_{2}, p}\right)}{\partial \sigma}=\frac{1+\alpha^{\sigma-1}}{1+\left(1+p^{\sigma-1}\right) \cdot \alpha^{\sigma-1}}-(\sigma-1) \frac{\left(\ln \alpha+\left(1+\alpha^{\sigma-1}\right) \cdot \ln p\right) \cdot(\alpha \cdot p)^{\sigma-1}}{\left(1+\left(1+p^{\sigma-1}\right) \cdot \alpha^{\sigma-1}\right)^{2}}
$$

For $\sigma \leq 1$ (with $\alpha>1$ ), the right hand side is unambiguously positive:

$$
\frac{\partial\left(\eta_{C_{2}, p}\right)}{\partial \sigma}>0
$$

For $\sigma>1$, this inequality can only be established numerically because the relative goods price $p$ is endogenous and cannot be expressed as an explicit function of the exogenous parameters.

Numerical simulations for $\alpha \in[1,10], \chi \in[0,10], \mu \in[0,1], \gamma \in[0,1)$ (implying $\sigma \in[1, \infty))$, and $\xi \in[0,1]$ confirm that the inequality also holds for $\sigma>1$.

This completes the proof:

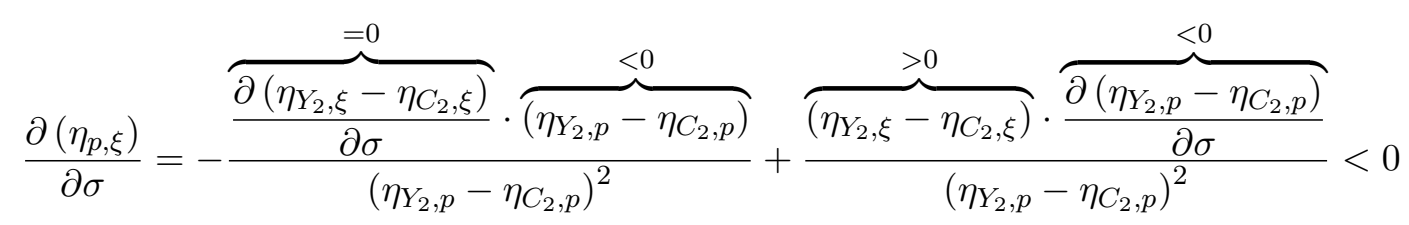

and therefore:

$$
\frac{\partial\left(\eta_{\tilde{j}, \xi}\right)}{\partial \sigma}=\underbrace{\frac{\partial\left(\eta_{\tilde{j}, p}\right)}{\partial \sigma}}_{=0} \cdot \underbrace{\eta_{p, \xi}}_{<0}+\underbrace{\eta_{\tilde{j}, p}}_{<0} \cdot \underbrace{\frac{\partial\left(\eta_{p, \xi}\right)}{\partial \sigma}}_{<0}>0
$$

\subsection{Description of the data}

This Appendix contains a description of the variables used in Section 3, sample statistics and a description of the unbalanced panel of OECD countries. 
Table 9: Description of the Variables

\begin{tabular}{|c|c|}
\hline \multicolumn{2}{|c|}{ Time Use Survey (Zeitbudgeterhebung) 1991/92 } \\
\hline$h p$ & total household home production (in minutes per day) \\
\hline$r h$ & paid help received by the household (in minutes per week) \\
\hline$\lambda$ & employment status ( $=0$ if not employed, $=1$ if employed) \\
\hline$\omega$ & time spent on gainful employment (in minutes per day) \\
\hline$K i d s 0-5$ & number of children in the household aged $0-5$ years \\
\hline Kids6 - 18 & number of children in the household aged $6-18$ years \\
\hline SchoolYrs $_{\text {Avg }}$ & average years of schooling of wife and husband \\
\hline SchoolYrs $s_{\text {Diff }}$ & difference in schooling years between husband and wife \\
\hline TrainYears & years of vocational training \\
\hline Inc & household income \\
\hline $\operatorname{Inc} c^{2}$ & household income squared \\
\hline$A g e_{A v g}$ & average age of wife and husband \\
\hline$A g e_{D i f f}$ & difference between the husband's and the wife's age \\
\hline Mid & region dummy (North Rhine-Westphalia, Hessen) \\
\hline \multirow[t]{2}{*}{ South } & region dummy \\
\hline & (Rhineland-Palatinate, Baden-Wuerttemberg, Bavaria) \\
\hline Urban & degree of urbanization of the region \\
\hline$G N P$ & per capita gross national product in the region \\
\hline TertSec & employment share of the tertiary sector \\
\hline Weekend & weekend dummy (= 1 if the interview was on a weekend) \\
\hline Unemp $_{R}$ & unemployment rate in the region \\
\hline \multicolumn{2}{|l|}{ OECD Data 1980-2003 } \\
\hline Participation (all) & Participation rate (Labor Force 20-65/Population 20-65) \\
\hline Participation (55-64 yrs) & Participation rate (aged 55-64) \\
\hline Working Hours & Share of average annual working hours in total annual hours ( 8760 \\
\hline GDP growth p.c & GDP growth per capita \\
\hline Employment Protection Legislation & EPL index, ranging from 1 to 20 (20=strictest regulation) \\
\hline Union Density & Share of union members among dependent workers (in \%) \\
\hline
\end{tabular}

Table 10: Data coverage in the unbalanced panel of OECD countries

\begin{tabular}{cccccc}
\hline Australia & Austria & Belgium & Canada & Denmark & Finland \\
$1980-2003$ & $1997-2003$ & $1985-2003$ & $1980-2003$ & $1985-2003$ & $1980-2003$ \\
\hline France & Germany & Greece & Iceland & Ireland & Italy \\
$1980-2003$ & $1993-2003$ & $1985-2002$ & $1993-2002$ & $1985-2003$ & $1980-2003$ \\
\hline Japan & Luxembourg & Netherlands & New Zealand & Norway & Portugal \\
$1980-2003$ & $1985-2002$ & $1989-2003$ & $1989-2003$ & $1980-2003$ & $1988-2003$ \\
\hline Spain & Sweden & Switzerland & Turkey & United Kingdom & United States \\
$1980-2003$ & $1980-2003$ & $1993-2003$ & - & $1986-2003$ & $1980-2003$ \\
\hline
\end{tabular}


Table 11: Descriptive Statistics: OECD Data

\begin{tabular}{llll}
\hline & Sample mean & Sample minimum & Sample maximum \\
\hline Unemployment Rate & 0.076 & 0.015 (LUX, 1991) & 0.240 (ESP, 1994) \\
Participation Rate (all) & 0.709 & $0.576(\mathrm{NL}, 1980)$ & 0.866 (ICE, 2000) \\
Participation Rate (55-64 years) & 0.484 & $0.222(\mathrm{BEL}, 1990)$ & 0.887 (ICE, 1995) \\
Working Hours & 0.195 & $0.153(\mathrm{NOR}, 2003)$ & $0.242(\mathrm{JAP}, 1980)$ \\
GDP Growth Rate p.c. & 0.022 & -0.069 (FIN, 1991) & 0.010 (IRE, 1997) \\
Union Density Rate & 40.204 & 8.600 (ESP, 1984) & 87.40 (SWE, 1994) \\
Employment Protection Rate & 2.119 & 0.200 (USA, all yrs) & 4.800 (POR, all yrs) \\
\hline
\end{tabular}

\subsection{Income}

In the Time Use Survey, income is recorded in the form of a range card question, i.e., the respondents report their income in predefined intervals instead of being asked the precise amount. This survey design is often chosen to achieve a higher response rate (Juster and Smith 1997; Winter 2002). In order to assign the household a continuous income, we combine the information about the lower and upper limits of the respective income intervals with additional information on household and personal characteristics. Interval-coded data can then be treated like an ordered response, where the cut-points are already known. We define a latent (continuous) variable income $\operatorname{Inc} c^{*}=x \beta+e$ where $e \mid x \sim N(0,1)$. If $\alpha_{1}<\operatorname{In} c^{*} \leq \alpha_{2}$, the observed income class is for example Inc $=2$ with the limits $\alpha_{1}$ and $\alpha_{2}$, and so forth. In the case of interval-coded data, these cut-points $\alpha$ are already known, so that only the parameters $\beta$ have to be estimated. The standard normal assumption made above changes to $\operatorname{Inc} c^{*} \mid x \sim N\left(x \beta, \sigma^{2}\right)$ where $\sigma^{2}=\operatorname{Var}\left(\operatorname{Inc} c^{*} \mid x\right)$ is assumed not to depend on $\mathrm{x} . \beta$ and $\sigma^{2}$ can then be estimated by maximum likelihood (Wooldridge 2002).

Table 12 (a) and (b) reports the regression results for men's and women's income. We use these results to assign each household member its predicted continuous income given her characteristics and income bracket. Then, we add up these individual incomes to obtain the household's income. Thus, we improve upon the common method of just choosing the midpoints as the income measure. However, like the midpoint approach, this more sophisticated method of generating a (continuous) income regressor and using it in the estimation of home production time and paid help can be problematic. While the usual OLS assumption that $\epsilon$ is uncorrelated with the $x$ suffices for consistency in Sections 3.3 and 3.4, the inference will generally be invalid because we ignore the sampling variation in $\widehat{I n c}$. Generally, the uncertainty in the estimate should be accounted for in the regression of interest. See Wooldridge (2002), chapter 6 for a discussion of generated regressors and chapter 14 for a general framework for handling these problems. In our case, the sampling variation in $\widehat{I n c}$ is very small. First, it is considerably lower than when using the midpoints, because we do not only use the income bracket information, but also the additional individual characteristics, $x$. Second, we observe relatively narrow income 
brackets which alone are already good income predictors. For these reasons, we do not adjust the inference in the second step.

Table 12: Regression results for (a) women's and (b) men's income, ordered probit with known cut-points

\begin{tabular}{|c|c|c|c|c|c|c|c|}
\hline \multirow[b]{2}{*}{$\lambda_{f}$} & \multicolumn{4}{|c|}{ (a) women's income } & \multicolumn{3}{|c|}{ (b) men's income } \\
\hline & -474.9722 & $(10.29)$ & $* * *$ & $\lambda_{m}$ & -1462.273 & $(5.18)$ & $* * *$ \\
\hline$\omega_{f}$ & 1.492634 & $(29.69)$ & $* * *$ & $\omega_{m}$ & 2.057012 & $(11.00)$ & $* * *$ \\
\hline$\omega_{f}^{2}$ & -0.0002054 & $(15.26)$ & $* * *$ & $\omega_{m}^{2}$ & -0.0002412 & $(7.70)$ & $* * *$ \\
\hline$A G E_{f}$ & 3.28296 & $(0.33)$ & & $A G E_{m}$ & 166.2939 & $(9.53)$ & $* * *$ \\
\hline$A G E_{f}^{2}$ & 0.0238836 & $(0.20)$ & & $A G E_{m}^{2}$ & -1.670301 & $(8.22)$ & $* * *$ \\
\hline SchoolYrs $s_{f}$ & 522.7379 & $(3.55)$ & $* * *$ & SchoolYr $s_{m}$ & 1469.907 & $(6.08)$ & $* * *$ \\
\hline SchoolYrs ${ }_{f}^{2}$ & -21.72323 & $(3.24)$ & $* * *$ & SchoolYrs ${ }_{m}^{2}$ & -57.73957 & $(5.21)$ & $* * *$ \\
\hline $\operatorname{TrainYrs}_{f}$ & -37.34202 & $(1.63)$ & & TrainYrs $s_{m}$ & 33.40076 & $(0.62)$ & \\
\hline $\operatorname{TrainYrs}_{f}^{2}$ & 33.25985 & $(6.67)$ & $* * *$ & $\operatorname{TrainYrs}_{m}^{2}$ & 39.11736 & $(3.93)$ & $* * *$ \\
\hline Urban & 58.76952 & $(3.04)$ & $* * *$ & Urban & 101.0078 & $(3.16)$ & $* * *$ \\
\hline$G N P$ & 0.0062472 & $(3.67)$ & $* * *$ & $G N P$ & 0.0035232 & $(1.27)$ & \\
\hline Unemp $_{R}$ & -21.75875 & $(3.43)$ & $* * *$ & Unemp $_{R}$ & -24.28667 & $(2.34)$ & $* *$ \\
\hline Weekend & 43.99512 & $(1.96)$ & $* *$ & Weekend & -6.385638 & $(0.17)$ & \\
\hline Constant & -3311.774 & $(4.02)$ & $* * *$ & Constant & -11815.06 & $(8.79)$ & $* * *$ \\
\hline Observations & 4110 & & & Observations & 4268 & & \\
\hline
\end{tabular}

\subsection{Sensitivity Analysis of Section 3.3}

This subsection reports the results of estimating a fixed effects model on the time spent on home production. We observe every household's time use over two diary days and use this panel structure in order to estimate a fixed effects model that filters unobserved heterogeneity.

Table 13: Fixed effects regression

\begin{tabular}{|c|c|c|c|c|c|c|c|}
\hline \multicolumn{8}{|c|}{ dependent variable: total household home production } \\
\hline$\omega_{f}$ & -.5561986 & $(-14.48)$ & $* * *$ & $\omega_{m}$ & -.3266689 & $(-11.67)$ & $* * *$ \\
\hline$\eta_{f}^{2}$ & -41.30521 & $(-2.64)$ & $* * *$ & $\eta_{m}^{2}$ & -17.01301 & $(-1.12)$ & \\
\hline Tuesday & -3.40505 & $(-0.33)$ & & Friday & 18.91802 & $(1.16)$ & \\
\hline Wednesday & -.6622015 & $(-0.05)$ & & Saturday & -41.88183 & $(-2.30)$ & $* *$ \\
\hline Thursday & 25.74003 & $(1.63)$ & & Sunday & -280.6594 & $(-16.93)$ & $* * *$ \\
\hline Constant & 799.7208 & $(40.47)$ & $* * *$ & & & & \\
\hline Obs. & 4304 & & & Overall $R^{2}$ & 0.30 & & \\
\hline
\end{tabular}




\section{References}

Aguiar, M. and E. Hurst (2005). Consumption vs. expenditure. Journal of Political Economy 113(5), 919-948.

Akerlof, G. A. and J. L. Yellen (1988). Fairness and unemployment. American Economic Review 78(2), 44-49.

Akerlof, G. A. and J. L. Yellen (1990). The fair wage-effort hypothesis and unemployment. Quarterly Journal of Economics 105(2), 256-283.

Banks, J., R. Blundell, and S. Tanner (1998). Is there a retirement-savings puzzle? American Economic Review 88(4), 769-788.

Beblo, M. (1999). Intrafamily time allocation: A panel-econometric analysis. In J. Merz and M. Ehling (Eds.), Time-Use Research - Data and Policy, pp. 473-489. BadenBaden: Nomos.

Becker, G. (1965). A theory of the allocation of time. Economic Journal 75 (299), 493508.

Blanchard, O. and J. Wolfers (2000). The role of shocks and institutions in the rise of european unemployment: The aggregate evidence. Economic Journal 110, 1-33.

Brines, J. (1994). Economic dependency, gender, and the division of labor at home. The American Journal of Sociology 100(3), 652-688.

Brück, T., J. P. Haisken-DeNew, and K. F. Zimmermann (2003). Creating low skilled jobs by subsidizing market-contracted household work. IZA Discussion Paper 958.

Cahuc, P. and A. Zylberberg (2004). Labor Economics. Cambridge, Massachussetts: The MIT Press.

Calmfors, L. and M. Hoel (1988). Work sharing and overtime. Scandinavian Journal of Economics 90(1), 45-62.

Calmfors, L. and M. Hoel (1989). Work sharing, employment, and shiftwork. Oxford Economic Papers 41(4), 758-773.

Corneo, G. G. (1995). Distributional implications of a shorter working week: An unpleasant note. Journal of Economics 62(1), 25 - 31.

Fehr, E. and S. Gächter (2000). Fairness and retaliation: The economics of reciprocity. Journal of Economic Perspectives 14(3), 159-181.

Greenstein, T. (2000). Economic dependency, gender, and the division of labor in the home: A replication and extension. Journal of Marriage and the Family 62(May 2000), 322-335.

Gronau, R. (1977). Leisure, home production, and work - the theory of the allocation of time revisited. Journal of Political Economy 85(6), 1099 - 1124.

Hamermesh, D. S. (1984). Consumption during retirement: The missing link in the life cycle. Review of Economics and Statistics 66(1), 1-7. 
Hank, K. (2001). The employment of domestic help and women's labor force participation in western germany. Schmollers Jahrbuch 121(1), 105-121.

Heathcote, J. (2002). Home production and retirement. Georgetown University.

Hunt, J. (1999). Has work-sharing worked in germany? Quarterly Journal of Economics 114(1), 117 - 148 .

Hurd, M. and S. Rohwedder (2003). The retirement-consumption puzzle: Anticipated and actual declines in spending at retirement. NBER Working Paper 9586.

Juster, F. T. and J. P. Smith (1997). Improving the quality of economic data: Lessons from the HRS and AHEAD. Journal of the American Statistical Association 92(440), $1268-1278$.

Kahnemann, D., J. Knetsch, and R. Thaler (1986). Fairness as a constraint on profit seeking: Entitlements in the market. American Economic Review 76(4), 728-41.

Logeay, C. and S. Schreiber (2006). Evaluating the effectiveness of the french worksharing reform. Applied Economics. forthcoming.

Lührmann, M. (2006). Essays on the Impact of Demographic Change on Capital, Goods and Labor Markets. Ph. D. thesis, MEA (Mannheim University).

OECD (1998). Employment Outlook 1998. Paris: OECD.

Schettkat, R. and W. Salverda (2004). Demand patterns and employment growth consumption and services in france, germany, the netherlands, the united kingdom and the united states. DEMPATEM Working Paper 13.

Van Deelen, M. and R. Schettkat (2004). Household demand patterns in west germany: 1978-1993. DEMPATEM Working Papers 5.

Van der Lippe, T., K. Tijdens, and E. De Ruijter (2004). Outsourcing of domestic tasks and time-saving effects. Journal of Family Issues 25(2), 216-240.

Weiss, M. (2004). Skill-biased technological change: Is there hope for the unskilled? MEA Discussion Paper 45-04.

Weiss, M. and A. Garloff (2005). Skill-biased technological change and endogenous benefits: The dynamics of unemployment and wage inequality. MEA Discussion Paper 100-05.

Winter, J. K. (2002). Bracketing effects in categorized survey questions and the measurement of economic quantities. SFB 504 Discussion Paper 35.

Wooldridge, J. M. (2002). Econometric Analysis of Cross Section and Panel Data. Cambridge, Massachusetts: MIT Press. 


\section{Discussion Paper Series}

Mannheim Research Institute for the Economics of Aging Universität Mannheim

To order copies, please direct your request to the author of the title in question.

\begin{tabular}{|c|c|c|c|}
\hline Nr. & Autoren & Titel & Jahr \\
\hline $88-05$ & $\begin{array}{l}\text { Felix Freyland ed. by } \\
\text { Axel Börsch-Supan }\end{array}$ & $\begin{array}{l}\text { Household Composition and Savings: An } \\
\text { Empirical Analysis based on the German SOEP } \\
\text { Data }\end{array}$ & 05 \\
\hline $89-05$ & Hendrik Jürges & $\begin{array}{l}\text { Unemployment, restrospective error, and life } \\
\text { satisfaction }\end{array}$ & 05 \\
\hline $90-05$ & Hendrik Jürges & $\begin{array}{l}\text { Gender Ideology, Division of Housework, and the } \\
\text { Geographic Mobility Families }\end{array}$ & 05 \\
\hline $91-05$ & $\begin{array}{l}\text { Hendrik Jürges } \\
\text { Wolfram F. Richter } \\
\text { Kerstin Schneider }\end{array}$ & $\begin{array}{l}\text { Teacher quality and incentives - Theoretical and } \\
\text { empirical effects of standards on teacher quality }\end{array}$ & 05 \\
\hline $92-05$ & $\begin{array}{l}\text { Hendrik Jürges } \\
\text { Kerstin Schneider }\end{array}$ & $\begin{array}{l}\text { Dynamische Lohneffekte beruflicher } \\
\text { Weiterbildung - Eine Längsschnittanalyse mit } \\
\text { den Daten des SOEP }\end{array}$ & 05 \\
\hline $93-05$ & Alexander Ludwig & $\begin{array}{l}\text { Moment estimation in Auerbach-Kotlikoff models: } \\
\text { How well do they match the data? }\end{array}$ & 05 \\
\hline $94-05$ & Alexander Ludwig & $\begin{array}{l}\text { Aging and Economic Growth: The Role of Factor } \\
\text { Markets and of Fundamental Pension Reforms }\end{array}$ & 05 \\
\hline $95-05$ & Melanie Lührmann & $\begin{array}{l}\text { Population Aging and the Demand for Goods \& } \\
\text { Services }\end{array}$ & 05 \\
\hline $96-05$ & $\begin{array}{l}\text { Jorge Gonzalez- } \\
\text { Chapela }\end{array}$ & On Measuring Convergence in the Use of Time & 05 \\
\hline $97-05$ & $\begin{array}{l}\text { Christina Benita } \\
\text { Wilke }\end{array}$ & $\begin{array}{l}\text { Rates of Return of the German PAYG System - } \\
\text { How they can be measured and how they will } \\
\text { develop }\end{array}$ & 05 \\
\hline $98-05$ & Karsten Hank & $\begin{array}{l}\text { Spatial Proximity and Contacts between Elderly } \\
\text { Parents and Their Adult Children: A European } \\
\text { Comparison }\end{array}$ & 05 \\
\hline $99-05$ & Matthias Weiss & $\begin{array}{l}\text { On the Evolution of Wage Inequality in } \\
\text { Acemoglu's Model of Directed Technical Change }\end{array}$ & 05 \\
\hline $100-05$ & $\begin{array}{l}\text { Matthias Weiss Alfre } \\
\text { Garloff }\end{array}$ & $\begin{array}{l}\text { Skill Biased Technological Change and } \\
\text { Endogenous Benefits: The Dynamics of } \\
\text { Unemployment and Wage Inequality }\end{array}$ & 05 \\
\hline $101-06$ & $\begin{array}{l}\text { Melanie Lührmann } \\
\text { Matthias Weiss }\end{array}$ & $\begin{array}{l}\text { Market Work, Home Production, Consumer } \\
\text { Demand and Unemployment among the } \\
\text { Unskilled }\end{array}$ & 06 \\
\hline
\end{tabular}

